\title{
EVOLVING ANIMAL-SOURCED FOODS AND LIVESTOCK MARKETS
}

Fantu Bachewe, Bart Minten, and Feiruz Yimer

\section{Introduction}

There is a strong desire by policymakers to improve nutritional outcomes in developing countries, given the often high levels of undernutrition, consequent high prevalence of stunted children, and the resultant high human and economic costs (Hoddinott et al. 2013). To address this problem, a strong emphasis is generally put on increasing diet diversity, on top of other interventions, given the well-established link between, for example, improved dietary quality and reduced stunting rates (Arimond and Ruel 2004). Recent research shows that animal-sourced foods (ASF) play an important part in the beneficial impact of higher dietary diversity, as a direct link has been shown worldwide between higher consumption levels of ASF and improved nutritional outcomes (Randolph et al. 2007; Leroy and Frongillo 2007; Weaver 2014; Black et al. 2008; Jin and Iannotti 2014; Iannotti et al. 2014; Givens et al. 2014). As ASF have more accessible crucial vitamins and minerals relative to plant-based foods and contain bioactive factors, they have been shown to be beneficial for physical growth and for brain development of children (Dror and Allen 2011, 2014). There also is increasing evidence that bone development is strongly associated with increased ASF consumption (Givens 2010).

In Ethiopia there is strong suggestive evidence on the link between the consumption of ASF (especially milk) and improved nutritional outcomes among children (Hoddinott, Headey, and Dereje 2015; Sadler and Catley 2009). However, ASF consumption in Ethiopia is low (Tafere and Worku 2012). Increasing consumption levels of these products is therefore desirable to improve nutritional indicators for the country's population. Previous research has shown that factors associated with low ASF consumption levels in Ethiopia are high prices (for example, Gordon, Tegegne, and Tadesse 2007; Tefera et al. 2010; Iannotti et al. 2012), shortage of ASF, particularly milk in urban areas (for example, Gordon, Tegegne, and Tadesse 2007; Tegene et al. 2013), fasting habits (FVI-Idele 2016), and lack of awareness regarding dietary 
diversity or the nutritional benefits of ASF (for example, Gordon, Tegegne, and Tadesse 2007; Tefera et al. 2010; Warren and Frongillo 2017). This work investigates the first issue in particular, examining price formation of ASF and livestock in Ethiopia.

Price formation of ASF is not well researched and therefore not well understood in Ethiopia. This is an important knowledge gap because the diversity and quantity of food consumed (and thereby the resultant nutritional outcomes) are strongly impacted by food and agricultural prices (for example, Brinkman et al. 2010). This is specifically so for ASF, which are often prohibitively priced for poor and vulnerable households to afford (for example, Iannotti et al. 2012). Although we are not aware of recent studies of ASF pricing in Ethiopia, a number of researchers have looked at the associated livestock markets in Ethiopia. ${ }^{1}$ Livestock prices are linked to many factors, including the type of livestock (Ayele et al. 2006; Teklewold et al. 2009), market institutions and transaction costs (Jabbar et al. 2008; Bellemare and Barrett 2006), weather and rainfall patterns (De Waal 1988), periodical cash needs of farmers, particularly to purchase food (Little, Debsu, and Tiki 2014), rising feed costs that are linked with increasing land scarcity (Mekasha et al. 2014; Negassa et al. 2012), and international trade (Tadesse, Lanos, and MasAsparisi 2014).

This chapter is aimed at filling this knowledge gap with respect to ASF prices, while also adding to existing knowledge on livestock price formation. Relying on a large-scale nationally representative price dataset that has been consistently collected in 116 urban retail markets in the country (Ethiopia, CSA 2017b), we study patterns of ASF prices in Ethiopia over the past decade. We find that ASF products are expensive compared to basic staples. This is important given high poverty levels and the relatively high share of food expenditures in the overall budget of an average Ethiopian (Worku et al. 2016). For example, Warren and Frongillo (2017) show that households do not consume ASF-even when they are aware of their nutritional benefits-because of high prices. As seen in other developing countries, this seemingly explains why only the relatively richer part of the population regularly

1 Several researchers have looked at price formation in food and agricultural markets in Ethiopia. Strong seasonality and spatial patterns have been shown to exist in these markets (Minten, Stifel, and Tamru 2014). While a number of factors that constrain the well-functioning of the markets persisted in the past (Rashid and Minot 2010; Rashid and Negassa 2011), these markets are growing and their efficiency is improving over time, seemingly driven by improved road and communication infrastructure, rapid urbanization, and the increasing demands from urban residents, based on their income growth and consequently increases in their willingness to pay for food (for example, Minten, Stifel, and Tamru 2014). 
consumes ASF. We also see significant seasonality in both prices and consumption of ASF. This is associated with large swings in demand, due to the timing of religious celebrations and the fasting periods that precede these religious events. We further find that there are significant spatial variations in ASF prices, with relatively higher prices in cities and in more commercially oriented livestock areas.

We find that there have been significant increases in real prices of ASF in the past decade, on the order of 33 percent, 36 percent, and 32 percent increases for beef, milk, and eggs, respectively. This is in contrast with cereal prices, which did not show such increases. While increases in ASF prices are good news for livestock producers, as their terms of trade improved, such price increases hamper the affordability of ASF, especially so for the poorer and more vulnerable populations in the country. As price elasticities are high for ASF products-Tafere and Worku (2012) estimate an elasticity of -0.73 for beef and -0.67 for dairy products-this implies that such price increases will have resulted in decreases in per capita consumption of beef and dairy products by almost 25 percent, holding other things constant, when we compare the end to the beginning of the decade. ${ }^{2}$

The results of these findings have important implications for agriculture and nutrition policy in Ethiopia. The Ethiopian government has a good track record with respect to improvement of cereal production in the country in the past decade. This improvement has been driven by a focus on a modernization of the cereal sector and on the increased adoption of modern technologies (Bachewe et al. 2015). It has been shown that changes in the cereal sector have brought about considerable improvements in poverty alleviation and calorie intake (World Bank 2014). However, in the further transformation process, ASF and "high-value" crops will have a more important role to play, given food preferences of consumers, but also because of their nutritional benefits. ${ }^{3}$ To increase diet diversity and improve nutritional outcomes in the country, ASF and "high-value" crops need to be made available at more affordable prices. This, in turn, points to the needs for more investments to increase livestock, ASF, and high-value crop production as well as to achieve a livestock production system that can accommodate the growing demand in ASF. This is important since most recent efforts to achieve nutritional improvements

2 The increasing incomes in the country, however, might have compensated for these increases in prices, since these products also have high-income elasticities (Tafere and Worku 2012).

3 As has been noted in other growing economies, the relative importance of cereals in total food expenditures is decreasing in Ethiopia. We are beginning to see a shift toward more preferred but also more expensive foods, including animal-sourced foods (Worku et al. 2016). 
in Ethiopia have focused on behavioral change communication (BCC) and improvements in other sectors, such as health, water, and sanitation. While important and successful (for example, Kim et al. 2016), improving access to and achieving low prices for these nutritious ASFs also have an important role to play in multidimensional efforts to improve nutritional outcomes.

The chapter gives background information on livestock and ASF consumption in Ethiopia. We discuss data and descriptive statistics, present findings on seasonal and spatial patterns in ASF and livestock prices, and look at changes over time in real prices and in terms of trade. We finish with the conclusions and implications of the findings.

\section{Background on Livestock and Animal-Sourced Foods in Ethiopia}

\section{Production and Consumption}

While numbers on livestock and livestock holdings in Ethiopia are uncertain and subject to debate, it is generally acknowledged that Ethiopia has the largest livestock population in Africa (Negassa et al. 2017). The Central Statistical Agency (CSA) of Ethiopia estimated that in 2014/2015 there were 56 million cattle, 29 million sheep, 29 million goats, and 57 million poultry (Ethiopia, CSA 2015a). ${ }^{4}$ Figure 8.1 illustrates the spatial distribution of the cattle population and the goat and sheep population in the country based on CSA livestock population data. These livestock species are shown to be densely concentrated in the central highlands of Ethiopia. However, the reported estimates do not account for the significant number of pastoralists-mostly in the eastern parts of the country-as CSA's regular data collection operations only cover sedentary parts of the country. ${ }^{5}$ Negassa et al. (2012) estimated that 20 percent of the cattle population and 40 percent of sheep and goats are held in these pastoralist areas.

On the consumption side, based on the nationally representative Household Consumption Expenditures Survey (HCES) conducted by CSA,

4 The Ethiopian Orthodox Christian Church and Islam - the two dominant religions in the country-do not permit pork consumption. Pig production, therefore, is rare in Ethiopia.

5 Livestock ownership per household in the Somali region is considerably higher and that in Afar is somewhat higher relative to average ownership in the central highlands. However, the map would likely still show a dense livestock population in the central highlands even if data were available for the eastern parts, because the central highlands are significantly more densely populated. 


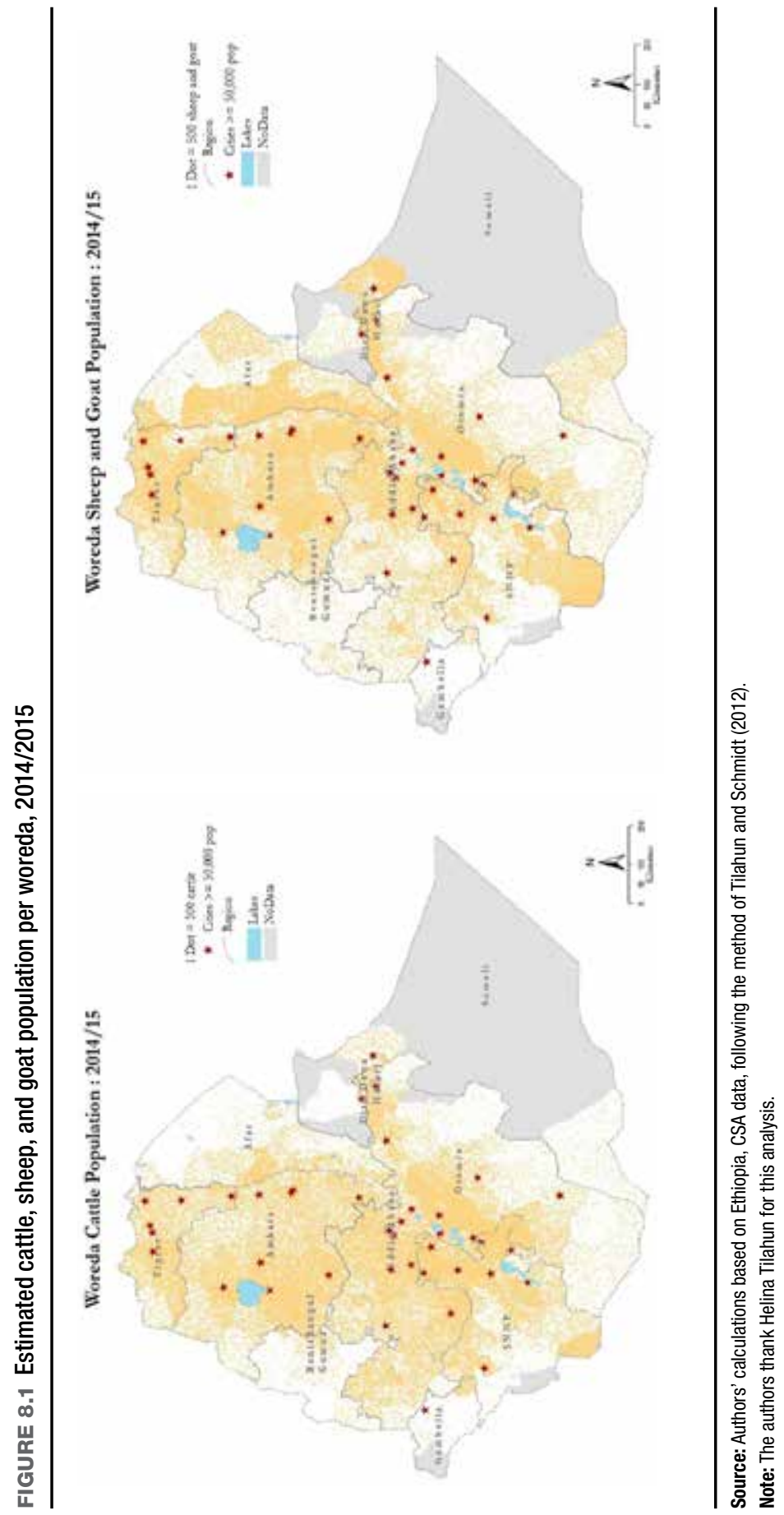


it was estimated in 2011 that 13.4 percent of consumption expenditures of an average Ethiopian was devoted to ASF. Of this expenditure, 42 percent was used for dairy products, 40 percent for beef, and 12 percent for sheep and goat meat. Expenditures on other ASF products (including poultry) are relatively minor. ${ }^{6}$ As seen in several other countries, ASF are mostly consumed by relatively better-off households (Tafere and Worku 2012). Worku et al. (2016) estimate that consumers in the richest quintile used 17.6 percent of their food budget for ASF. This compares to only 6.6 percent by the poorest quintile, about one-third the budget share level of the rich. Moreover, expenditure shares of ASF are significantly higher in urban areas (14.3 percent) relative to rural areas ( 9.8 percent). Within urban areas, differences are further noted with higher consumption in bigger cities (16.2 and 16.1 percent in Addis Ababa and secondary towns, respectively) compared to smaller ones (13.2 percent).

The high consumption of ASF in cities as well as rapid urbanization in Ethiopia is leading to rapid increases in the size of rural-urban livestock and ASF value chains. This is illustrated by the rapid increase in the number of animals slaughtered in Addis Ababa, where an estimated one-quarter of the meat consumption in the country occurs (FVI-Idele 2016). ${ }^{7}$ The number of sheep and goats and number of cattle slaughtered in Addis Ababa, respectively, increased from 75,015 and 151,977 head in 2007 to 175,818 and 232,822 head in 2015, or an annual increase of 12.9 percent and 6.3 percent, respectively (based on data reported by FVI-Idele 2016).

\section{International Trade}

Ethiopia has increasingly become more integrated to international trading systems. ${ }^{8}$ This trend is also seen in the livestock sector, as can be observed in

6 Average consumption levels of meat were around 5 kilograms per year per adult equivalent, based on these HCES data from 2011. This is relatively low but not out of line for a country with GDP levels of Ethiopia (Msangi 2016).

7 While slaughtering of sheep and goats is mostly done informally, this is not the case with cattle since beef is mostly sold through butcheries, which are required by law to buy from certified slaughterhouses. Sheep and goat meat is most often directly bought by consumers, so the animals are slaughtered informally in backyard settings. It is estimated that one-third of cattle slaughtering is informal or illegal in Addis Ababa (FVI-Idele 2016). Data on the number of cattle slaughtered in slaughterhouses (formal slaughter) might therefore provide a good indication of underlying trends in urban consumption.

8 The National Bank of Ethiopia reports that, measured as a share of GDP, real value of both exports and imports on average declined during 2004/2005-2014/2015. However, in absolute terms, exports and imports were 70 percent and 134 percent higher in 2014/2015 than in 
increases in formal exports of livestock as well as in imports of ASF. On the import side, Ethiopia is increasingly importing dairy products, most importantly milk powder. The value of dairy products Ethiopia imported tripled from US\$6 million in 2005 to $\$ 18$ million in 2015 (Figure 8.2). Meat imports are also growing but are much lower in value ( $\$ 1.5$ million in 2015). Meanwhile, exports from the livestock sector are relatively much more important and have grown impressively over the past decade. The value of exports of live animals increased more than tenfold from \$24 million in 2005 to $\$ 332$ million in 2015; those of meat products increased from $\$ 18$ million in 2005 to $\$ 107$ million in 2015 ; and raw hides and skins increased by just below 50 percent, from $\$ 67$ million to $\$ 98$ million over the same period. Part of the increases in exports has been achieved through closer oversight by the government, leading to a shift from informal to formal markets (Farmer 2010). However, there are still significant informal exports of live animals (Negassa et al. 2012). Farmer (2010) estimated informal exports to be seven times the volume of formal exports in 2005/2006 (Farmer 2010), while USAID (2013) estimated more recently that informal exports made up 80 percent of total exports.

Given the increasing importance of live animal exports, we present further information on those in Figure 8.3. On the left we note that the cattle are the most important live animal exports as they made up around 60 percent of all live animal exports over the past decade. On the right we see the destination countries for these live animal exports. We see surprisingly large changes by year. However, the most important destinations in recent years are Djibouti, Egypt, and Somalia.

We also document to what extent the livestock sector is relying on international trade to obtain some of its modern inputs. The evolution of imports of feed and vaccines is illustrated in Figure 8.4. There have been significant increases, possibly showing important recent transformation and the increasing commercial orientation for some parts of the livestock subsector. For example, inputs of pre-mixed feeds have increased tenfold over the past ten years, with their value standing at more than US\$5 million in 2015. The value of veterinary inputs also increased fivefold over the period considered. However, while increasing rapidly, the levels are still low. To put these 
FIGURE 8.2 Ethiopia's import and export of livestock and animal-sourced foods, 2005-2015
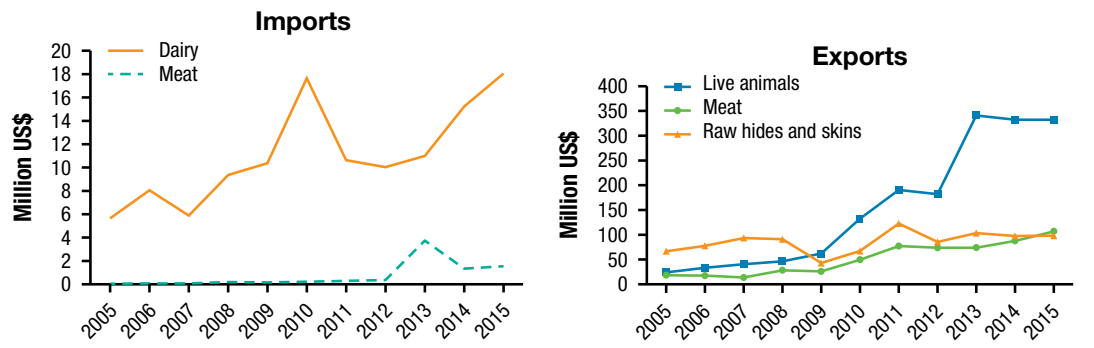

Source: Authors' calculations based on UN Comtrade data (UN Comtrade 2017).

FIGURE 8.3 Ethiopia's exports of live animals, composition, and destination countries, 2005-2015
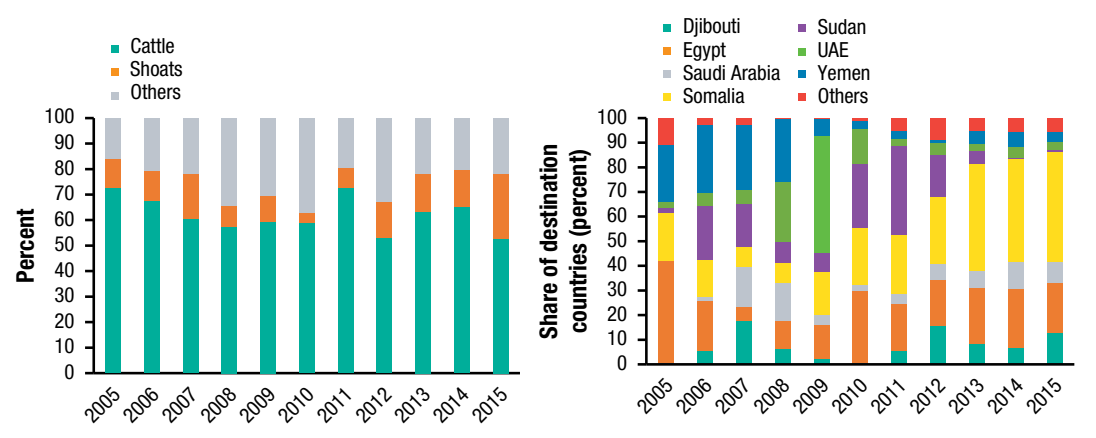

Source: Authors' calculations based on UN Comtrade data (UN Comtrade 2017).

Note: "Shoat" combines sheep and goats into a single category.

FIGURE 8.4 Imports of inputs used in livestock production in Ethiopia, 2007-2015

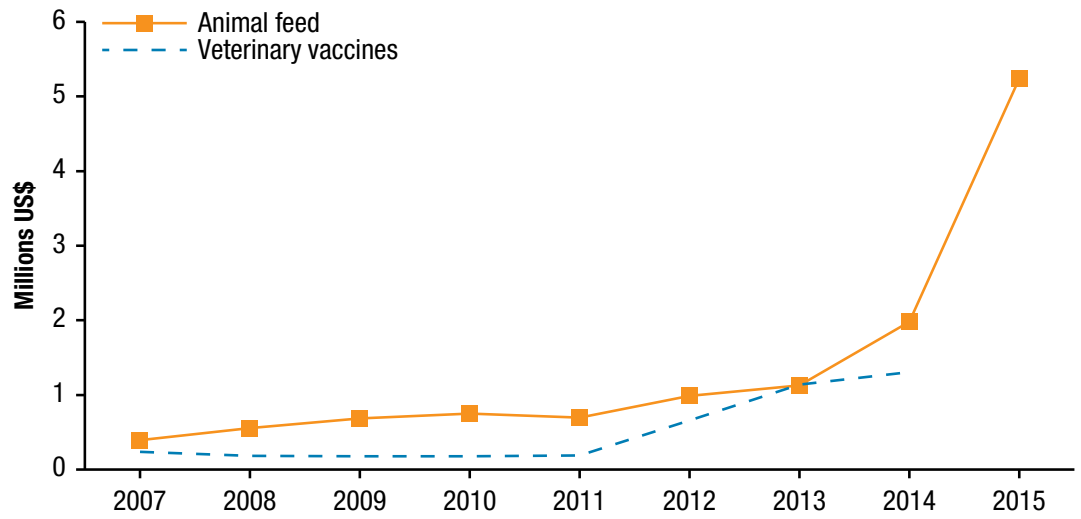

Source: Authors' calculations based on UN Comtrade data (UN Comtrade 2017). 
imports in perspective, imports of chemical fertilizer used for crop agriculture amounted to more than $\$ 500$ million in 2016 (UN Comtrade 2017).

\section{Data and Descriptive Statistics}

\section{Data}

The price data used in this study are collected as part of the CSA's Consumer Price Survey (Ethiopia, CSA 2017b). These data were collected in 116 urban retail markets in all regions of Ethiopia between January 2007 and December 2016. The number of markets in each region is approximately proportional to the region's share of the total urban population to ensure a sufficient degree of national representativeness (Figure 8.5). Thirty-two markets are surveyed in Southern Nations, Nationalities, and Peoples (SNNP) region, 24 in Oromia, and 20 in Amhara (the three biggest regions), while 12 markets are surveyed in Addis Ababa (by far the largest urban center with officially more than three million residents). The smaller regions include only a handful of markets.

CSA enumerators, who reside permanently in these markets, collect price and weight/volume data from traders, retailers, and consumers. For each item a maximum of three price quotations are collected from three different retailers in the first 15 days of each month in the European calendar, though enumerators are encouraged to survey the same retailers across months if possible. In the case of livestock, prices are collected on cattle (heifers, cows, bulls, and oxen), small ruminants (goats, sheep), and poultry (hens, cocks). Prices of 11 types of ASF are collected: beef, camel meat, milk (processed and unprocessed cow milk, goat milk, camel milk, and milk powder), eggs, and processed dairy products (yoghurt, cheese, and butter). Most of our descriptive analyses rely on price data of 8 of the 11 ASF items since data on camel meat, camel milk, and goat milk is unavailable in most months for most markets. We also study trends in real prices of cattle and ASF using CSA's Producer Survey Data (Ethiopia, CSA 2017c). The producer price surveys are also conducted monthly and mostly in the same manner as the retail price surveys, but they differ in that they include only primary crop and livestock outputs.

9 As a result, four of the eight ASF items are excluded from the dataset: beef, pasteurized cow milk, powdered milk, and yoghurt. Although the producer price data leaves out one-quarter of the items considered in this study, its use, albeit briefly, is justified as most rural residents purchase ASF and livestock, particularly oxen for use in crop production, from these markets. For instance, the HCES (Household Consumption Expenditures Survey) (Ethiopia, CSA 2011) data 
FIGURE 8.5 Administrative zones covered by Ethiopia Central Statistical Agency retail price data

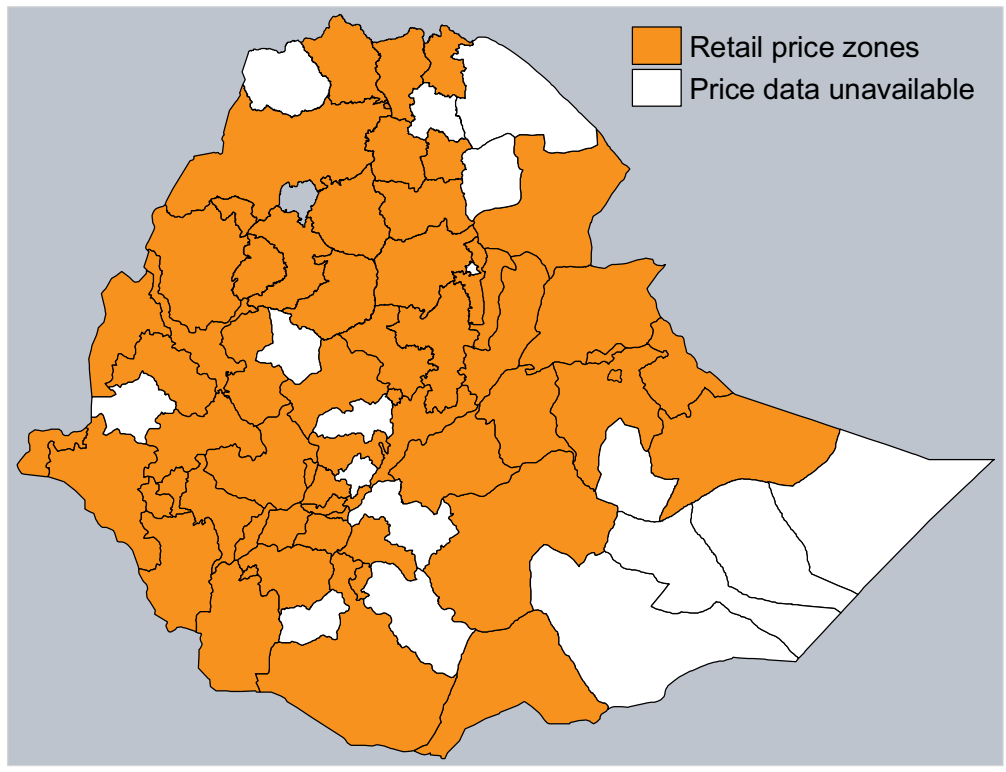

Source: Authors' mapping using CSA retail price data (Ethiopia, CSA 2017b).

We deflate prices using the regional general Consumer Price Index (CPI) calculated by CSA. This is done to express all prices in December 2011 birr (Ethiopia, CSA 2017a). ${ }^{10}$ As the weight of individual products in the Consumer Price Index (CPI) is relatively low and given the lack of any reasonable alternative, we rely on the regional CPI to deflate the retail prices. We use a deseasonalized index, since one of our interests is studying seasonal patterns of prices that typically characterize the agricultural and food sectors. ${ }^{11}$

indicates that 78 percent of the dairy consumed in rural areas in 2010/2011 was own-produced while 20.3 percent was purchased. Similarly, 35 percent of the eggs and about 77 percent of the meat consumed was purchased.

10 Unless specified otherwise, all prices in this chapter are in real December 2011 birr. The US dollar-to-birr exchange rate in that month was US $\$ 1=17.19$ birr.

11 To construct such an index, we first calculate a 12-month moving average of the real price for each item. Then we deflate/normalize the price series so constructed by dividing it to its January 2007 values. Accordingly, the price index has a value of one in January 2007 and it is greater/less than one in months with deseasonalized prices greater/less than January 2007 prices. 


\section{Descriptive Statistics}

Table 8.1 provides summary statistics of the real prices of livestock and ASF over the period 2007-2016. The dataset used in our analyses comprises a large number of observations for livestock, ranging from 10,898 observations for cows and 11,479 for oxen to 12,260 for sheep and 12,676 for cocks. The high number of observations indicate the wide presence of this type of livestock in these retail markets. In the case of ASF, we see wide availability of prices for beef, unpasteurized milk, butter, and eggs. Yoghurt, cheese, powdered milk, and pasteurized milk are less available. The price data least available are for goat milk, camel milk, and camel meat, which are mostly consumed in pastoralist areas (Afar and Somali regions) and in Dire Dawa, Harari, and parts of Oromia regions.

As might be expected, we see large price differences across livestock categories. Poultry are the cheapest livestock category with median prices for a hen of about 43 birr (US\$2.5). Prices for a hen are about 10 percent the price of a sheep, which had a median price of 438 birr (US\$25). The price of a bull is more than five times the price of a sheep. While there are obvious differences in the quantity of meat that can be obtained from different livestock categories, the price of beef is the most expensive at 71 birr per kilogram, on average, while the average price of meat coming from sheep and goats is estimated at 45 birr per kilogram, and that of poultry ranged from 52 to 78 birr per kilogram.

In the case of ASF, beef is sold at slightly higher prices than camel meat. However, it is to be noted that camel meat is mostly found in eastern pastoralist areas, close to production areas and away from major urban centers, such as Addis Ababa, and its lower price might possibly be explained by this. Unpasteurized cow milk is the cheapest of all dairy products. The median prices of camel and goat milk are on average 22 percent and 26 percent higher than the median price of cow milk. Using medians, pasteurized cow milk is almost twice as expensive as nonpasteurized milk, implying that likely relatively richer households consume this type of milk. Looking at processed dairy products, butter has the highest price with a median price more than tenfold that of milk. The price of cheese is more than twice that of milk, and the price of yoghurt is 65 percent higher than that of milk.

We also present at the bottom of Table 8.1 prices per kilogram of the staple cereals in the country. When these prices are compared to prices of ASF, the latter have much higher prices. Compared to the prices of maize, the most important cereal in calorie terms in the country, median beef prices are 16 times more expensive over the period considered. Relative to the price of maize, unpasteurized cow milk prices are more than double, and a dozen of 
TABLE 8.1 Prices in 2011 birr, descriptive statistics, 2007-2016

\begin{tabular}{|c|c|c|c|c|c|c|}
\hline Category & Unit & Observations & Mean & Median & $\begin{array}{l}\text { Standard } \\
\text { deviation }\end{array}$ & $\begin{array}{l}\text { Coefficient } \\
\text { of variation }\end{array}$ \\
\hline \multicolumn{7}{|l|}{ Livestock } \\
\hline Heifer (2-4 years) & piece & 10,905 & $2,074.3$ & $1,973.7$ & 703.7 & 0.34 \\
\hline Cow (4 years and above) & piece & 10,898 & $3,117.4$ & $2,953.0$ & 993.0 & 0.32 \\
\hline Bull (2-4 years) & piece & 11,142 & $2,607.4$ & $2,403.8$ & 992.3 & 0.38 \\
\hline 0x (4 years and above) & piece & 11,479 & $5,029.1$ & $4,750.4$ & $1,629.4$ & 0.32 \\
\hline Sheep (10-15 kilograms) & piece & 12,260 & 460.9 & 438.5 & 165.7 & 0.36 \\
\hline Goat (10-15 kilograms) & piece & 12,158 & 425.0 & 393.3 & 161.1 & 0.38 \\
\hline Hen (indigenous) & piece & 12,593 & 44.7 & 43.1 & 15.3 & 0.34 \\
\hline Cock (indigenous) & piece & 12,676 & 66.7 & 64.5 & 21.0 & 0.31 \\
\hline \multicolumn{7}{|l|}{ Animal-sourced foods } \\
\hline Beef & kilograms & 11,697 & 71.0 & 70.2 & 16.6 & 0.23 \\
\hline Camel meat & kilograms & 1,018 & 63.1 & 65.1 & 19.6 & 0.31 \\
\hline Cow milk unpasteurized & liter & 11,102 & 9.5 & 9.1 & 2.5 & 0.27 \\
\hline Cow milk pasteurized & liter & 2,392 & 18.8 & 17.1 & 6.0 & 0.32 \\
\hline Camel milk & liter & 1,438 & 11.8 & 11.1 & 4.1 & 0.35 \\
\hline Goat milk & liter & 469 & 11.7 & 11.5 & 3.4 & 0.29 \\
\hline Powdered milk & 450 grams & 7,853 & 99.8 & 99.4 & 14.6 & 0.15 \\
\hline Yoghurt & liter & 8,884 & 15.8 & 15.0 & 5.2 & 0.33 \\
\hline Cheese & kilograms & 5,997 & 23.8 & 21.1 & 11.4 & 0.48 \\
\hline Butter & kilograms & 11,694 & 98.1 & 96.3 & 22.0 & 0.22 \\
\hline Egg & dozen & 12,837 & 20.3 & 20.1 & 4.7 & 0.23 \\
\hline \multicolumn{7}{|l|}{ Cereals } \\
\hline Teff (mixed) & kilograms & 12,592 & 10.5 & 10.2 & 2.3 & 0.22 \\
\hline Wheat (white) & kilograms & 12,416 & 7.6 & 7.3 & 2.0 & 0.26 \\
\hline Barley (mixed) & kilograms & 12,512 & 7.5 & 7.2 & 2.0 & 0.27 \\
\hline Maize (white) & kilograms & 11,823 & 4.7 & 4.4 & 1.6 & 0.35 \\
\hline Sorghum (white) & kilograms & 11,040 & 6.0 & 5.8 & 2.3 & 0.38 \\
\hline
\end{tabular}

Source: Authors' computations using Ethiopia, CSA price data.

Note: Exchange rate December 2011: 1 US $\$=17.19$ birr.

eggs was five times higher. On the other hand, milk is less expensive than teff. Based on the national household survey of 2011, Worku et al. (2016) compare the calorie prices of different food groups in average consumption baskets in Ethiopia and find that ASF calorie prices are on average 9.5 times more expensive than those of cereals. Finally, we compare the price ratios of ASF 
TABLE 8.2 Cereal-ASF (animal-sourced foods) relative calorie price ratios, Ethiopia compared with other regions

\begin{tabular}{lccccc}
\hline Region & $\begin{array}{c}\text { Cow's milk, } \\
\text { fresh }\end{array}$ & $\begin{array}{c}\text { Cow's milk, } \\
\text { processed }\end{array}$ & $\begin{array}{c}\text { Chicken } \\
\text { eggs }\end{array}$ & Meat & Fish \\
\hline High income & 3.2 & 2.2 & 3.0 & 2.0 & 4.3 \\
Latin America and Caribbean & 3.9 & 3.0 & 4.9 & 3.2 & 3.4 \\
Middle East and North Africa & 10.1 & 3.1 & 6.1 & 6.2 & 6.0 \\
South, Central, and Southeast Asia & 7.8 & 3.8 & 6.2 & 6.5 & 5.3 \\
Western and Central Africa & 16.5 & 4.0 & 9.9 & 5.3 & 5.0 \\
Eastern and Southern Africa & 13.9 & 5.8 & 9.1 & 5.6 & 6.1 \\
Ethiopia & 10.4 & - & 19.6 & 52.9 & 38.1 \\
\hline
\end{tabular}

Source: Numbers for all regions (except Ethiopia) from Table 9 in Headey, Hirvonen, and Hoddinott (2018); Ethiopia data are from Bachewe et al. (forthcoming).

Note: $-=$ data not available.

in Ethiopia with other countries (Table 8.2). They indicate the significantly higher price ratios observed in Ethiopia compared to other countries. While the consumption of ASF obviously has benefits other than providing calories, these price differences indicate the challenge of assuring affordability of those products in Ethiopia where assuring food security remains a policy priority.

\section{Seasonal and Spatial Patterns}

\section{Seasonality}

Seasonal patterns are a defining characteristic of agriculture all over the world (for example, Sahn 1989). These seasonal movements are often linked to inherent constraints to consistent year-round supplies due to climatic and, most important, rainfall patterns. This is also the case in Ethiopia. Rainfall is unimodal in the west and north of the country with rainfall mostly falling between June and September and one main crop harvest (meher), while it is bi-modal in the east and southeast of the country, giving rise to a second season $($ belg $)$ in those areas. Moreover, rainfall is more reliable in the west and south of the country compared to other parts. As the production of feed for livestock is linked to this rainfall pattern, it induces seasonal patterns in the sector. Farmer (2010) shows that seasonality is an important factor for pastoralist households as rangelands can support fewer animals during the dry season, leading owners to sell livestock during the dry season or migrate to areas with better feed availability, while holding on to livestock during the 
wet season. For farmers in the highlands, fewer sales of livestock occur during the rainy period as feed is more easily available and cattle are needed for crop cultivation.

We also note significant seasonality in demand. One important characteristic of ASF consumption, particularly in Ethiopia, is its link with religion. An estimated 43 percent of the population in Ethiopia are Orthodox Christians (Ethiopia, CSA 2009), and their religion is characterized by important constraints on food intake, especially related to ASF. Figure 8.6, based on the Household Consumption and Expenditures Survey (HCES) of 2011, shows how quantities of ASF consumed vary over the course of the year for rural and urban residents. We see peaks in the beginning of the year (for the festivities of Ethiopian Christmas and Timket), in April (for Easter), and in September (for the New Year and Meskel). We see similar patterns in rural as well as urban areas, although levels are lower in the former areas as discussed above. The major consumption peaks associated with the major religious events are preceded by troughs, which are linked with fasting periods that come before and culminate during these important celebrations. This is especially so for Christmas, which occurs on January 7 every year, and Easter, which mostly occurs in April. During the fasting periods of Orthodox Christians-the Lent leading up to Easter during which the fasting period lasts up to 56 days and the one before Christmas, which lasts for about 40 days-no ASF are consumed. While there are other fasting periods during the year, they are much shorter. ${ }^{12}$ This reduction in consumption of ASF also shows up in slaughterhouse data in Addis Ababa. The number of head of cattle and of sheep and goats slaughtered in the "Christian hall" of the slaughterhouse in the month before Easter typically drops to one-quarter the level of other months (FVIIdele 2016). No such seasonality is seen for the "Muslim hall" during the Muslim major fasting season of Ramadan, and there is no evidence of higher activity at the end of Ramadan or for the Eid festivities.

Seasonal changes in demand seemingly drive changes in prices of livestock and ASF. A summary of the monthly price indexes is reported in Table 8.3 for different livestock categories. The results show that all seasonal indexes for all livestock categories are higher than 1.0 in January, February, April, May, and September, illustrating to what extent these religious events are associated

12 On top of these long fasting periods, Orthodox Christians do not eat ASF on Wednesdays and Fridays throughout the year, except in the two months after Easter. It has been estimated that the total number of days that clergy (priests, nuns, monks) are not allowed to eat ASF amounts to 250 per year (Ayenew et al. 2009). For nonclergy practicing Orthodox Christians, the number of fasting days amounts to between 166 and 180 . 
FIGURE 8.6 Consumption of animal-sourced foods in Ethiopia, by month (2011)

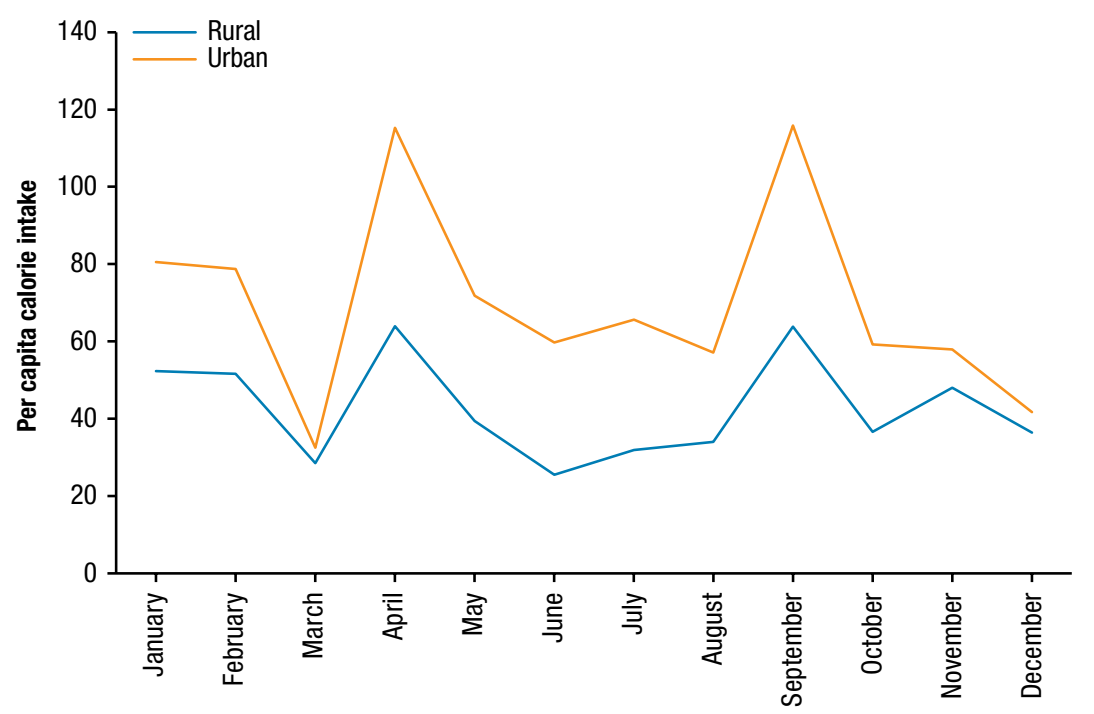

Source: Adjusted from Hirvonen, Taffesse, and Hassen (2016).

TABLE 8.3 Seasonal price indexes of livestock in Ethiopia, 2007-2016

\begin{tabular}{lcccccc}
\hline & \multicolumn{6}{c}{ Livestock } \\
\cline { 2 - 7 } Month & Sheep & Goat & Cow & Bull & 0x & Hen \\
\hline January & 1.03 & 1.02 & 0.99 & 1.01 & 1.01 & 1.11 \\
February & 0.98 & 0.98 & 0.98 & 0.98 & 0.97 & 1.02 \\
March & 0.96 & 0.97 & 0.97 & 0.99 & 0.96 & 0.99 \\
April & 1.02 & 1.03 & 1.01 & 1.01 & 1.01 & 1.07 \\
May & 1.02 & 1.03 & 1.02 & 1.03 & 1.04 & 1.01 \\
June & 0.99 & 0.99 & 1.02 & 1.01 & 1.02 & 0.94 \\
July & 0.99 & 0.99 & 1.01 & 1.00 & 1.02 & 0.92 \\
August & 0.99 & 0.99 & 1.01 & 1.00 & 1.00 & 0.93 \\
September & 1.06 & 1.05 & 1.03 & 1.01 & 1.04 & 1.08 \\
October & 1.00 & 0.99 & 0.99 & 0.99 & 0.99 & 0.98 \\
November & 0.98 & 0.97 & 0.98 & 0.98 & 0.97 & 0.97 \\
December & 0.97 & 0.97 & 0.98 & 0.98 & 0.96 & 0.98 \\
Amplitude & 0.10 & 0.08 & 0.06 & 0.05 & 0.08 & 0.19 \\
\hline
\end{tabular}

Source: Authors' calculations based on Ethiopia, CSA price data.

Note: Seasonal price indexes were calculated over the January 2007-December 2016 period using the percentage moving average method. In this method the original data values in the time-series (or real prices of the items in a given month) are expressed as a ratio of the 12-month moving average real prices of the items in that month. 
with higher prices. ${ }^{13}$ Slightly higher indexes for the prices of oxen/bulls/ cows during June through August are also noted, possibly because of demand for cultivation during the meher season. The lowest prices are noted during August, when fodder is easily available, as well as in October, November, and December. Seasonal amplitudes are not that large and vary between 5 percent and 10 percent for cattle and for sheep and goats. It is highest for poultry, for which prices vary 19 percent over the year in the case of hens. Ayele and Rich (2010) also link the low prices of poultry with regular outbreaks of Newcastle disease that typically occur in the late spring.

In Table 8.4 seasonal indexes are reported for several ASF. A similar pattern emerges as in the case of livestock. We see increases of prices at the time of major religious celebrations and a decrease during July/August, when livestock feed is easily available, products are more plentiful, and milk yields are higher. Prices are also lower at the end of the year during or just after crops are harvested and when the stock of crop-residue, which is used as livestock feed, is at its maximum. The September peak for ASF is much less pronounced than in the case of livestock.

\section{Spatial Patterns}

We next look at livestock and ASF price variation by region, using average prices over the 2007-2016 period (Table 8.5 ). We note significant variation by region. For example, the price of oxen is more than 50 percent higher in Addis Ababa compared to the Afar region. Similar variations are noted for other types of livestock. Overall, prices for Addis Ababa are consistently above the national median. The difference varies from 23 percent for cocks to 98 percent for goats. Prices are also higher than the national median for the cities of Dire Dawa and Harari, except for poultry. Prices for livestock are also relatively higher in the western region of Benishangul-Gumuz (BG), seemingly linked with the hostile environment there for livestock production due to warm and humid conditions and the presence of tsetse fly (SID-Consult 2010).

Prices in the SNNP region, though, are consistently and significantly lower for all types of livestock. ${ }^{14}$ Prices for most livestock are also low in the lowland and pastoralist areas of Somali. This is not the case for all types of livestock, however, as cattle prices are higher than the median. The breed sold in Afar markets is almost exclusively Danakil, which is among the lowest valued,

13 Except for cows in January.

14 The only exception is cock. 
TABLE 8.4 Seasonal price indexes of animal-sourced food in Ethiopia, 2007-2016

\begin{tabular}{lccccccc}
\hline & \multicolumn{7}{c}{ Animal-sourced food } \\
\cline { 2 - 8 } Month & Beef & Cow milk & Goat milk & Yoghurt & Cheese & Butter & Eggs \\
\hline January & 0.98 & 1.00 & 1.04 & 1.00 & 1.02 & 0.97 & 1.02 \\
February & 0.95 & 1.00 & 1.02 & 1.00 & 1.02 & 0.96 & 1.00 \\
March & 0.96 & 1.00 & 1.00 & 1.00 & 0.97 & 0.99 & 0.94 \\
April & 0.97 & 1.00 & 1.01 & 0.99 & 1.00 & 1.11 & 0.94 \\
May & 1.00 & 1.00 & 1.00 & 1.00 & 1.05 & 1.11 & 1.01 \\
June & 1.02 & 1.00 & 0.98 & 1.00 & 1.03 & 1.05 & 1.00 \\
July & 1.02 & 1.00 & 0.98 & 1.00 & 0.98 & 0.99 & 0.99 \\
August & 1.03 & 1.00 & 0.99 & 1.00 & 0.98 & 0.98 & 0.99 \\
September & 1.03 & 1.00 & 1.03 & 1.00 & 1.02 & 1.01 & 1.06 \\
October & 1.02 & 1.00 & 1.01 & 1.00 & 0.99 & 0.95 & 1.04 \\
November & 1.01 & 1.00 & 0.98 & 0.99 & 0.98 & 0.93 & 1.00 \\
December & 0.99 & 0.99 & 0.96 & 1.00 & 0.95 & 0.93 & 0.98 \\
Amplitude & 0.07 & 0.01 & 0.08 & 0.01 & 0.09 & 0.18 & 0.12 \\
\hline
\end{tabular}

Source: Authors' calculations based on Ethiopia, CSA price data.

Note: Seasonal price indexes were calculated over the January 2007-December 2016 period using the percentage moving average method. In this method the original data values in the time-series (or real prices of the items in a given month) are expressed as a ratio of the 12-month moving average real prices of the items in that month.

while the breed sold in Harari region, the Harari breed, has the highest value. All sorts of breeds are sold in Addis Ababa markets, which is why cattle prices in Harari region are generally higher than those in Addis Ababa, but lower for other livestock.

The price of sheep is lowest in the Somali region, a major supply region for export markets. Despite the large herd of livestock and its remoteness, the Afar region shows surprisingly high prices for cattle overall. However, there are significant variations in breeds over the country with different quality premiums attached to it (Teklewold et al. 2009). Sheep and goats from lowland areas of Somali and Afar regions have a higher fat content, and their meat is perceived not to "darken" when prepared. Consequently, such meat is preferred in export markets. Sheep and goats from lowlands are therefore more destined to export markets compared to those of the highlands, which are more used by domestic consumers. Comparing livestock prices, without quality considerations, is therefore not straightforward. Doing this more detailed analysis is left for future research.

Median prices of ASF are presented by region in Table 8.6. We note again significant variation in prices across regions. Prices of beef and milk 


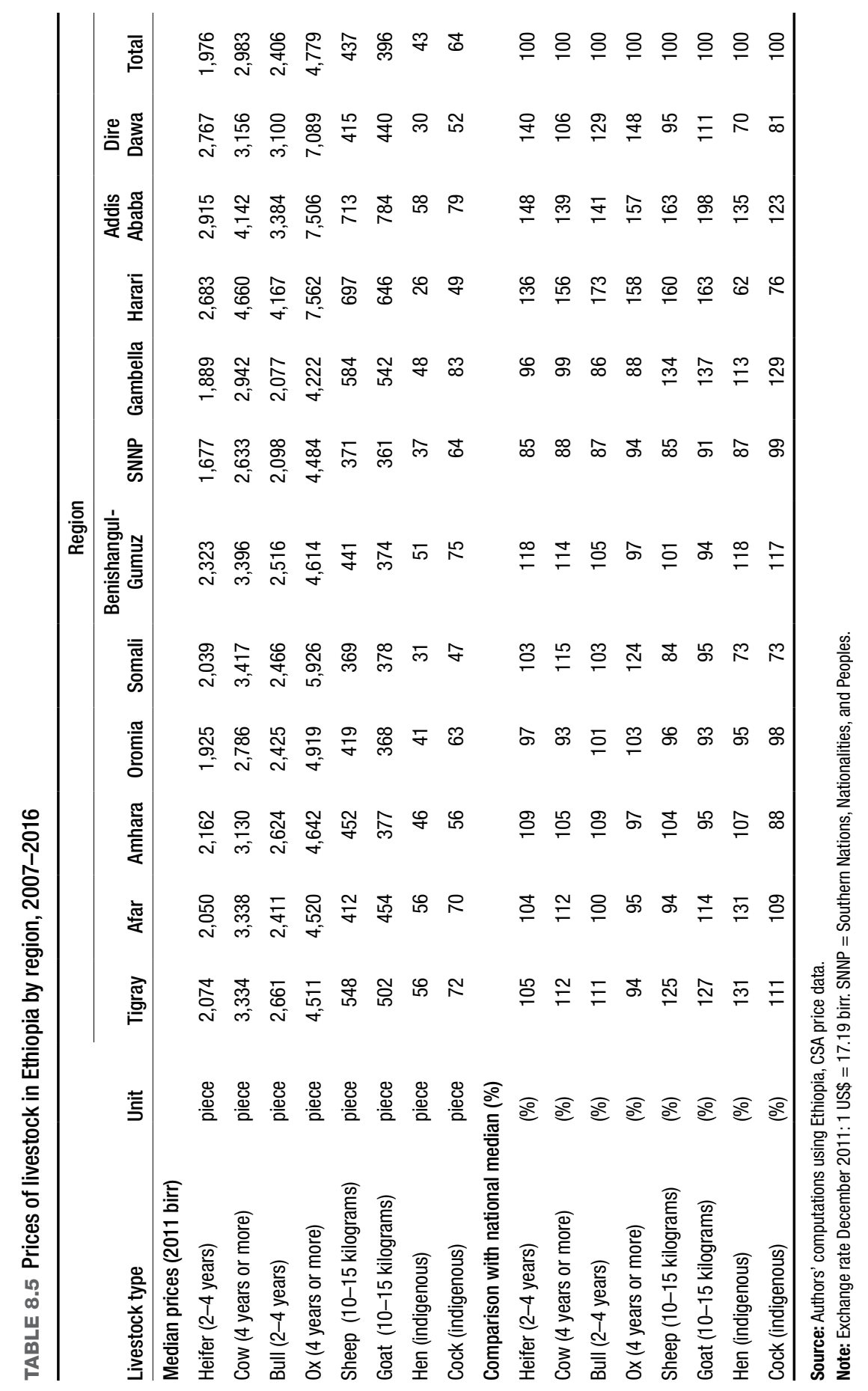




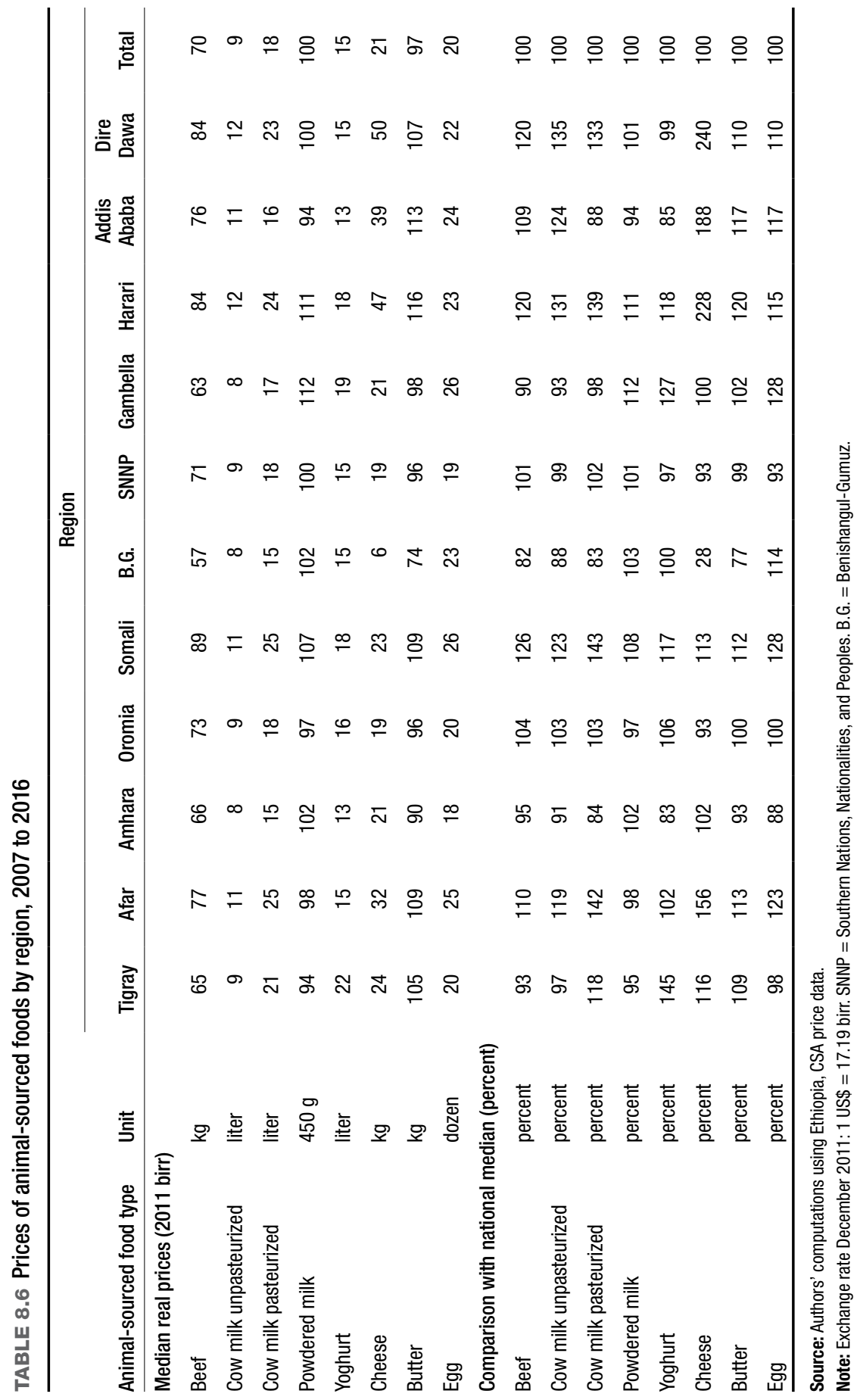


are relatively low in the northern part of the country-that is, Tigray and Amhara. Beef and milk prices in Tigray are 7 percent and 3 percent lower than the national median, respectively. This compares to 5 percent and 9 percent, respectively, in the Amhara region. Prices are also low for these products in the western regions of Benishangul-Gumuz and Gambella. Prices for beef and cow milk are high in the lowlands of Somali and Afar. Processed dairy product prices are also high in Somali and Afar, seemingly as there is little habit of processing milk in those settings. FAO (2017) notes that pastoralists and agro-pastoralists mostly consume milk fresh and as yoghurt and ghee.

ASF prices are also high in cities, particularly in the eastern cities of Harari and Dire Dawa compared to the capital Addis Ababa, which has the highest or second highest median prices for all livestock types and the lowest prices for some ASF items. Prices for pasteurized cow milk and yoghurt are among the lowest in Addis Ababa. This might possibly be explained by the considerable development of the dairy sector around Addis Ababa (Minten et al. 2018). ${ }^{15}$ Improved dairy processing plants combined with high demand allows for economies of scale, which seems to have contributed to relatively low prices in the capital compared to other cities.

Egg prices are also high in cities. They are lower than the national median in the three major agricultural regions of the country (Tigray, Amhara, and SNNP) and at par with the median in the Oromia region. Prices are also very high in pastoralist areas, seemingly as holding chicken is less conducive for seminomadic lifestyles; in addition, chicken are susceptible to heat stress, and most breeds are not well adapted to these hot areas (Nyoni, Grab, and Archer 2019).

Semiurban and rural areas around cities are often suppliers of food to these cities and therefore are usually well integrated with the end markets in the cities (Minten, Stifel, and Tamru 2014). As a result, one would expect prices in these areas to be lower than in the cities, with the differences in prices reflecting marketing costs. We present supplying areas and urban prices in the case of eggs, milk, sheep, and oxen, comparing the median prices of Addis Ababa and the surrounding Shewa zones (east, west, and north Shewa in Oromia, and north Shewa in Amhara) over the 2007-2016 period (Figure 8.7). Prices in Addis Ababa are all above the prices in the surrounding areas. More important, these prices have a close relationship during the whole period, except for oxen prices, which appeared to move in different directions and were wider

15 Two-thirds of the current dairy processing plants in Ethiopia are based in Addis Ababa or its surrounding areas. 
FIGURE 8.7 Real prices of sheep, oxen, eggs, and milk in Addis Ababa and surrounding Shewa zones, 2007-2016
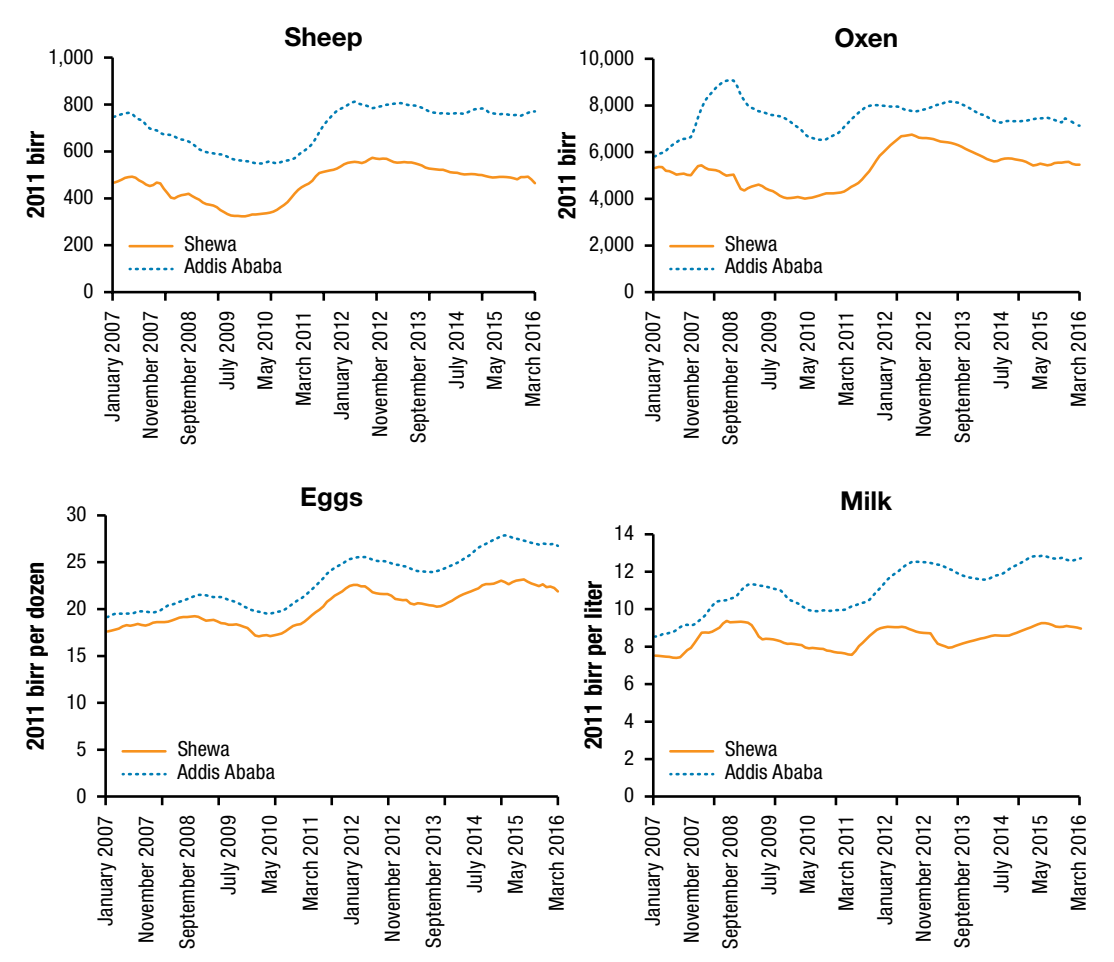

Source: Authors' calculations based on Ethiopia, CSA price data. Note: Exchange rate December 2011: 1 US\$ $=17.19$ birr.

apart during mid-2007 to December 2008. Despite the wide differences in oxen prices in the beginning of the period, the differences are rather stable at the end of the period. Price differences are rather stable for sheep but increasing toward the end. In particular, Addis Ababa sheep prices were 37 percent higher than prices in Shewa in an average month in 2011, and this price gap increased to 56 percent in 2016. Differences between Addis Ababa and Shewa milk and egg prices have also slowly but consistently increased during the period. ${ }^{16}$ More in-depth research would be needed to explain these increasing trends in marketing costs between rural and urban areas.

16 The gap between Addis Ababa and Shewa milk prices increased from 17 percent in an average month in 2007 to 40 percent in 2016. The oxen price gap increased from 23 percent to 33.4 percent, while the egg price gap increased from 8 percent to 20 percent during the same period. 


\section{Price Evolution over Time}

\section{Real Animal-Sourced Foods and Livestock Prices}

We next look at the extent that livestock and ASF prices have changed over the past decade. Retail prices of cows, bulls, and oxen are presented for the years 2007, 2011, and 2016 in Table 8.7. Real prices in 2011 were at similar (or even lower) levels than in 2007. However, there has been a significant increase since 2011. By 2016 real prices of cattle had risen between 10 percent and 13 percent relative to 2007 prices. Sheep and goats show similar upward trends, with prices 22 percent and 26 percent higher in 2016, respectively, while they also were higher in 2011. Finally, chicken prices increased the highest of all-prices of cocks were 46 percent higher in 2016 than a decade earlier. In the case of ASF, we see similar increases in retail prices over time (Table 8.8). Beef prices increased by 33 percent between 2007 and 2016. Cow milk and egg prices increased by 36 percent and 32 percent, respectively. Important increases are also seen for processed dairy products and for imported powdered milk.

We also use CSA's producer price dataset (Ethiopia, CSA 2017c) to study trends in prices of livestock and four of the eight ASF items included in the rural producer price dataset. In general, similar price increases are noted as in urban retail prices. Table 8.7 indicates that real producer cattle prices increased by 5 percent to 10 percent, while the increase was 14 percent in sheep, 24 percent in goats, and by more than 18 percent in poultry. Producer livestock prices in 2016 were lower than retail prices ranging from 14 percent (for hens) to 30 percent (for oxen). Moreover, growth in producer prices was lower relative to retail prices for all livestock types. However, livestock types with rapidly/slowly growing retail prices generally showed rapid/slow growth in producer prices. Real producer prices of cheese were essentially the same as retail prices in 2016, while retail prices were at least 18 percent higher than producer prices for the remaining three items (Table 8.8). However, growth rates in producer prices of these ASF items was generally higher than growth in retail prices.

Figure 8.8 presents zonal maps indicating real prices at the beginning and at the end of the past decade for the three most important ASF-beef, milk, and eggs. Here, an increase in price is indicated by a change of colors from light to darker green and vice versa. Accordingly, the overall darker colors on the right illustrate the increase in prices of the three ASF items over the past decade. In the case of beef, we note relatively lower prices and a relatively lower change in the north of the country. However, we note a considerable increase 
TABLE 8.7 Price evolution for livestock in Ethiopia, 2007, 2011, and 2016

\begin{tabular}{|c|c|c|c|c|c|c|}
\hline \multirow[b]{2}{*}{ Livestock type } & \multicolumn{3}{|c|}{ Urban retail prices } & \multicolumn{3}{|c|}{ Rural producer prices } \\
\hline & 2007 & 2011 & 2016 & 2007 & 2011 & 2016 \\
\hline \multicolumn{7}{|c|}{ Median real prices (2011 birr, per piece) } \\
\hline Heifer (2-4 years) & 1,866 & 1,811 & 2,059 & 1,636 & 1,407 & 1,713 \\
\hline Cow (4 years and above) & 2,732 & 2,788 & 3,105 & 2310 & 2127 & 2536 \\
\hline Bull (2-4 years) & 2,285 & 2,216 & 2,547 & 2,041 & 1,816 & 2,168 \\
\hline $0 x$ ( 4 years and above) & 4,405 & 4,250 & 4,992 & 3,606 & 3,258 & 3,858 \\
\hline Sheep (10-15 kilograms) & 393 & 422 & 479 & 345 & 345 & 392 \\
\hline Goat (10-15 kilograms) & 349 & 376 & 440 & 292 & 319 & 363 \\
\hline Hen (indigenous) & 38 & 39 & 48 & 36 & 34 & 42 \\
\hline Cock (indigenous) & 54 & 58 & 78 & 50 & 50 & 65 \\
\hline \multicolumn{7}{|c|}{ Comparison with national median in 2007 (\%) } \\
\hline Heifer (2-4 years) & n.a. & 97 & 110 & n.a. & 86 & 105 \\
\hline Cow (4 years and above) & n.a. & 102 & 114 & n.a. & 92 & 110 \\
\hline Bull (2-4 years) & n.a. & 97 & 111 & n.a. & 89 & 106 \\
\hline $0 x$ (4 years and above) & n.a. & 96 & 113 & n.a. & 90 & 107 \\
\hline Sheep (10-15 kilograms) & n.a. & 107 & 122 & n.a. & 100 & 114 \\
\hline Goat (10-15 kilograms) & n.a. & 108 & 126 & n.a. & 109 & 124 \\
\hline Hen (indigenous) & n.a. & 102 & 128 & n.a. & 96 & 118 \\
\hline Cock (indigenous) & n.a. & 109 & 146 & n.a. & 101 & 132 \\
\hline
\end{tabular}

Source: Authors' calculations based on Ethiopia CSA price data

Note: Exchange rate December 2011: 1 US\$ = 17.19 birr. n.a. = not applicable.

in the east, central, and southern parts of the country. The map suggests that relative beef prices have especially gone up in those areas that are well integrated in commercial livestock circuits.

Similarly, cow milk prices are relatively low and seem to have stayed the same or changed little over the past ten years in the northern part of the country. Although milk prices were already higher in the south and east of the country in 2007, that difference seems to even have widened over the decade. Real milk prices around the capital Addis Ababa do not seem to have increased very much over time, possibly driven by the development of this active periurban dairy value chain. Eggs also show similar patterns, a worsening over time overall, a relatively stable-to-slow increase in the north, around Amhara and Tigray, and worsening in the most southern, eastern, and western zones of the country. 
TABLE 8.8 Price evolution for animal-sourced foods in Ethiopia, 2007, 2011, and 2016

\begin{tabular}{|c|c|c|c|c|c|c|c|}
\hline \multirow[b]{2}{*}{ Animal-sourced foods type } & \multirow[b]{2}{*}{ Unit } & \multicolumn{3}{|c|}{ Urban retail prices } & \multicolumn{3}{|c|}{ Rural producer prices } \\
\hline & & 2007 & 2011 & 2016 & 2007 & 2011 & 2016 \\
\hline \multicolumn{8}{|l|}{ Median real prices (2011 birr) } \\
\hline Beef & kilograms & 62 & 56 & 82 & & & \\
\hline Cow milk unpasteurized & liter & 7 & 9 & 10 & 6 & 7 & 8 \\
\hline Cow milk pasteurized & liter & 14 & 17 & 17 & & & \\
\hline Powdered milk & 450 grams & 77 & 97 & 100 & & & \\
\hline Yoghurt & liter & 13 & 15 & 16 & & & \\
\hline Cheese & kilograms & 18 & 18 & 22 & 15 & 16 & 22 \\
\hline Butter & kilograms & 83 & 101 & 100 & 71 & 82 & 85 \\
\hline Egg & dozen & 17 & 20 & 22 & 12 & 15 & 18 \\
\hline \multicolumn{8}{|c|}{ Comparison with national median in 2007 (\%) } \\
\hline Beef & $(\%)$ & n.a. & 90 & 133 & & & \\
\hline Cow milk unpasteurized & $(\%)$ & n.a. & 118 & 136 & n.a. & 130 & 141 \\
\hline Cow milk pasteurized & $(\%)$ & n.a. & 122 & 122 & & & \\
\hline Powdered milk & $(\%)$ & n.a. & 126 & 129 & & & \\
\hline Yoghurt & $(\%)$ & n.a. & 115 & 122 & & & \\
\hline Cheese & $(\%)$ & n.a. & 101 & 125 & n.a. & 105 & 146 \\
\hline Butter & $(\%)$ & n.a. & 122 & 120 & n.a. & 116 & 120 \\
\hline Egg & $(\%)$ & n.a. & 116 & 132 & n.a. & 123 & 142 \\
\hline
\end{tabular}

Source: Authors' calculations based on Ethiopia, CSA price data.

Note: Exchange rate December 2011: 1 US\$ = 17.19 birr. n.a. = not applicable.

As ASF are obtained from livestock, we assess to what extent price increases of ASF and livestock have been linked over the past decade. To do so, we plot different pairs of ASF and livestock prices (Figure 8.9) and compute correlation coefficients of paired monthly average price indexes and percentage changes in prices. As one would expect, we see strong correlations in prices, indicating the close link of ASF and livestock sector performance. Moreover, there are fairly high correlations in price changes of the items considered. Beef prices seem more volatile than bull prices-as prices of the latter went relatively lower and higher than bull prices over the period considered-but the correlation coefficient of price indexes is still high at 0.94 while correlation of price growth rates is 0.51 . Beef prices in 2011 dropped significantly compared to bull prices, possibly because of price-fixing of beef by the government in the beginning of that year (Hassan 2011). The price-fixing led to less meat being brought to the market, and seemingly only those in need of cash were willing 
FIGURE 8.8 Real prices of beef (birr per kilogram), milk (birr per liter), and eggs (birr per dozen), 2007 and 2016 by zone (2011 birr)
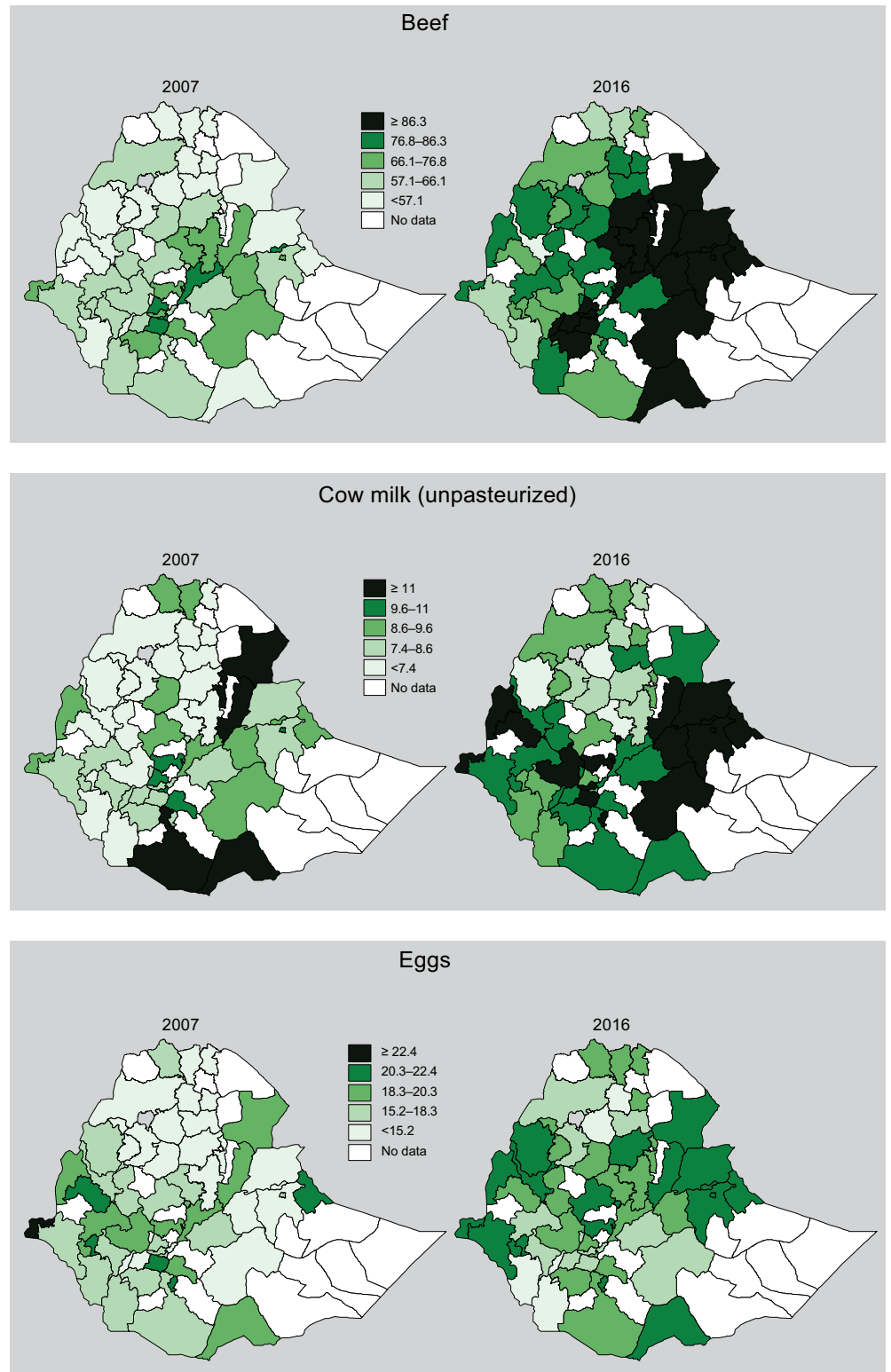

Source: Authors' calculations based on Ethiopia, CSA price data. Note: Exchange rate December 2011: 1 US $\$=17.19$ birr. 
FIGURE 8.9 Correlations of animal-sourced foods and livestock price indexes (January $2007=1.0$ )
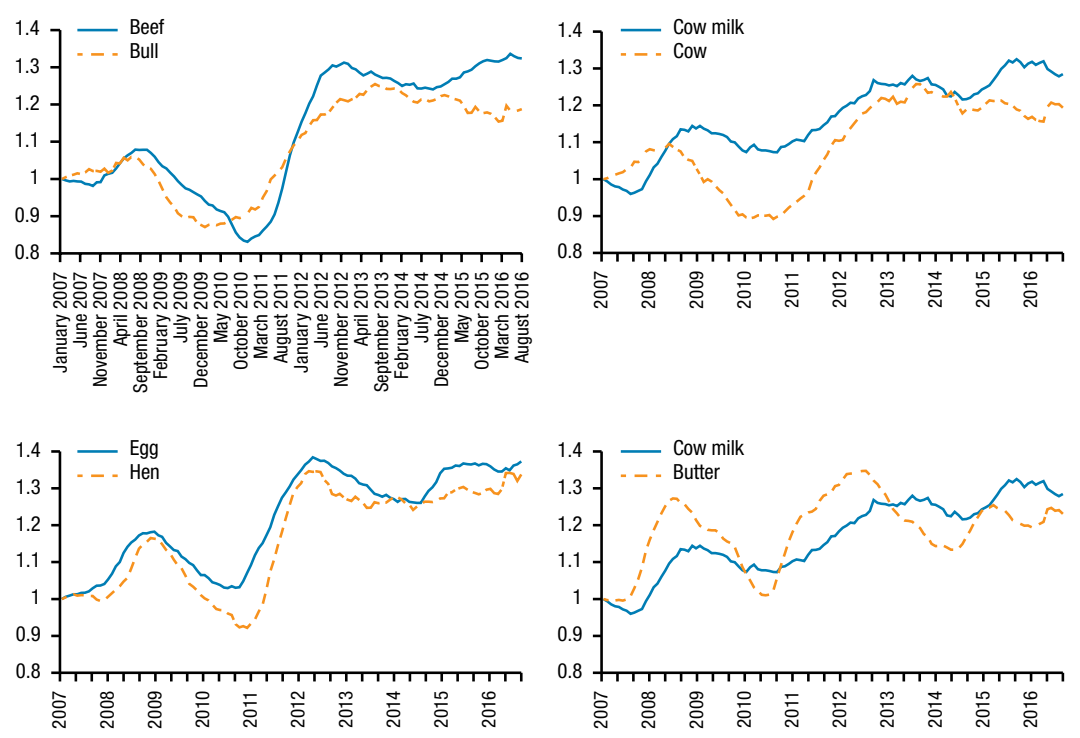

Source: Authors' calculations based on Ethiopia, CSA price data.

to sell their oxen. ${ }^{17}$ Cow milk and cow prices are less correlated with a correlation coefficient of 0.78 for price indexes and 0.31 for price growth rates. Eggs and hens, however, are characterized by a very high correlation coefficient of 0.96 for price indexes and 0.68 for price growth rates. We note in this case the disruption of the price-fixing done in the beginning of 2011 as the prices of hens in that period were the lowest of the whole decade. Butter and milk are also less correlated (at 0.60 for prices and 0.30 for price growth rate). In any case, the figure suggests overall that the strong increases in prices of ASF are associated with increases in livestock prices.

\section{Animal-Sourced Foods and Livestock versus Other Food Prices}

Since increasing the consumption of ASF would imply at least a partial trade from other major products in the consumption basket, we compare to what

17 On January 6, 2011, the government announced a list of 18 products for which it fixed prices (Hassan 2011). However, as several products were coming to be in short supply, most of the price caps were lifted in late May 2011. 
FIGURE 8.10 Annual per capita food consumption in 2011 in Ethiopia, by food type and region (kilograms per capita per year)

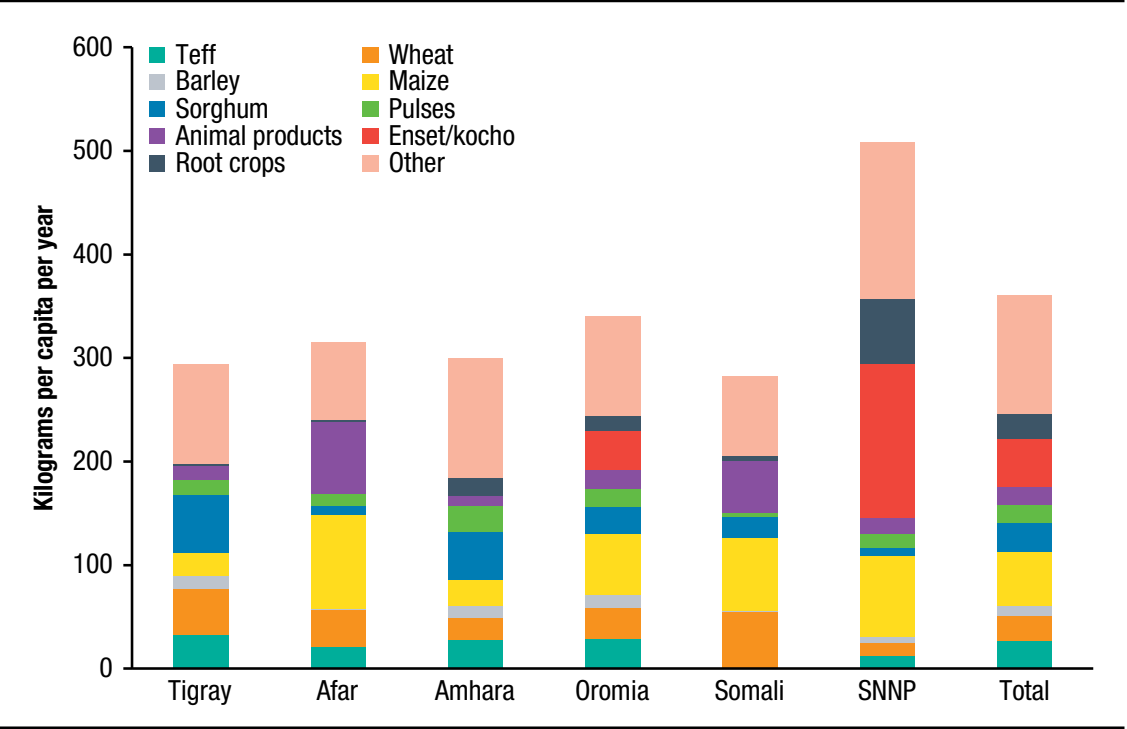

Source: Authors' calculations from CSA HCES (Ethiopia, CSA 2011).

Note: SNNP = Southern Nations, Nationalities, and Peoples.

extent the real prices of cereals changed relative to real prices of livestock and ASF products over the past decade. ${ }^{18}$ To do so, we first examine the quantity of different crops and products consumed. Figure 8.10 shows these data for the four major crop-producing regions as well as for the Afar and Somali regions. We use the average consumption basket from the Household Consumption Expenditures Survey (HCES) in 2011. Figure 8.10 illustrates that cereals are, in quantity terms, very important in these regions. They comprise 60 percent of the average consumption basket in Tigray, decreasing to 53 percent in Afar and 56 percent in Somali, and still remain at 50 percent in the Amhara and Oromia regions. In contrast, they comprise only 24 percent of the quantity consumed in SNNP due to the high levels of consumption of enset and root crops there.

18 CSA data indicate that more than 80 percent of the population in 2015 was engaged in crop production; nearly 86 percent of crop farmers produced one or more type of cereals and consumed 66 percent of the cereals output (Ethiopia, CSA 2013, 2015b, 2015c). In the same year, 73 percent of the total crop area was used to produce cereals (Ethiopia, CSA 2015c). 
TABLE 8.9 Terms of trade of livestock relative to cereals in Ethiopia, 2007, 2011, and 2016

\begin{tabular}{|c|c|c|c|c|}
\hline \multirow[b]{2}{*}{ Livestock type } & \multirow[b]{2}{*}{ Unit } & \multicolumn{3}{|c|}{ Year } \\
\hline & & 2007 & 2011 & 2016 \\
\hline \multicolumn{5}{|c|}{ Terms of trade (in terms of $100 \mathrm{~kg}$ of cereal) } \\
\hline Heifer ( $2-4$ years) & piece & 3.3 & 2.9 & 3.8 \\
\hline Cow (4 years and above) & piece & 5 & 4.4 & 5.6 \\
\hline Bull (2-4 years) & piece & 4 & 3.6 & 4.8 \\
\hline $0 x$ (4 years and above) & piece & 8 & 7 & 9.2 \\
\hline Sheep $(10-15 \mathrm{~kg})$ & piece & 0.7 & 0.7 & 0.9 \\
\hline Goat $(10-15 \mathrm{~kg})$ & piece & 0.6 & 0.6 & 0.8 \\
\hline Hen (indigenous) & piece & 6.5 & 6.1 & 8.9 \\
\hline Cock (indigenous) & piece & 9.4 & 9.2 & 13.7 \\
\hline \multicolumn{5}{|c|}{ Comparison with national median in 2006 (percent) } \\
\hline Heifer ( $2-4$ years) & percent & n.a. & 88 & 116 \\
\hline Cow (4 years and above) & percent & n.a. & 89 & 113 \\
\hline Bull (2-4 years) & percent & n.a. & 90 & 120 \\
\hline $0 x$ (4 years and above) & percent & n.a. & 88 & 115 \\
\hline Sheep $(10-15 \mathrm{~kg})$ & percent & n.a. & 94 & 120 \\
\hline Goat (10-15 kg) & percent & n.a. & 97 & 127 \\
\hline Hen (indigenous) & percent & n.a. & 94 & 138 \\
\hline Cock (indigenous) & percent & n.a. & 98 & 146 \\
\hline
\end{tabular}

Source: Authors' calculations based on CSA price data.

Note: The following ratio is used to calculate terms of trade $=$ (real price of a head of livestock/100 kilograms of per capita consumption weighted real cereal prices) for all livestock types except hens, for which the denominator is 1 kilogram of per capita consumption weighted real cereal prices. n.a. = not applicable.

We use these consumption data, together with CSA's retail price series, to compute the terms of trade of each ASF/livestock type as a ratio of the real prices of ASF/livestock to per capita consumption weighted real cereal prices. The results of this exercise are provided in Table 8.9 and Table 8.10.

To buy 1 kilogram of beef in 2016, one would have needed 15 kilograms of cereals (Table 8.10). This compares to 10.7 kilograms in 2007. This change in terms-of-trade corresponds to a 40 percent higher price of beef relative to cereals - a cereal farmer wanting to buy a kilogram of beef would need 4.3 kilograms more of cereals in 2016 than in 2007 to do so. A similar deterioration is seen in the case of milk, where prices expressed in kilograms of cereals deteriorated by 41 percent over the past decade. Egg prices also showed a deterioration of 39 percent. A similar exercise is done for livestock, indicating to what 
TABLE 8.10 Terms of trade of animal-sourced foods relative to cereals in Ethiopia, 2007, 2011, and 2016

\begin{tabular}{lcrrr}
\hline & & \multicolumn{3}{c}{ Year } \\
\cline { 3 - 5 } ASF type & Unit & 2007 & 2011 & 2016 \\
\hline Terms of trade (compared to 1 kg of cereal) & & & \\
Beef & $\mathrm{kg}$ & 10.7 & 8.8 & 15.1 \\
Cow milk unpasteurized & liter & 1.3 & 1.4 & 1.9 \\
Cow milk pasteurized & liter & 2.4 & 2.9 & 3.5 \\
Powdered milk & 450 gr & 14.1 & 15.5 & 18.1 \\
Yoghurt & liter & 2.4 & 2.4 & 3.2 \\
Cheese & kg & 3.1 & 3.1 & 4 \\
Butter & kg & 14.3 & 16.3 & 18.5 \\
Egg & dozen & 2.8 & 3.1 & 4 \\
Comparison with national median in 2006 (percent) & & \\
Beef & percent & n.a. & 82 & 140 \\
Cow milk unpasteurized & percent & n.a. & 103 & 141 \\
Cow milk pasteurized & percent & n.a. & 122 & 146 \\
Powdered milk & percent & n.a. & 111 & 129 \\
Yoghurt & percent & n.a. & 101 & 134 \\
Cheese & percent & n.a. & 98 & 129 \\
Butter & percent & n.a. & 114 & 130 \\
Egg & percent & n.a. & 107 & 139 \\
\hline & & & &
\end{tabular}

Source: Authors' calculations based on CSA price data.

Note: The following ratio is used to calculate terms of trade $=$ (real price of a unit of ASF $/ 1$ kilogram of per capita consumption weighted real cereal prices). n.a. $=$ not applicable.

extent livestock producers can buy more cereals with the sales of their livestock (Table 8.9) or how much more product cereal producers must sell to buy each type of livestock. The results show that cereal producers' terms-of-trade clearly deteriorated. The increase in the quantity of cereals needed to buy livestock ranged from 15 percent (1.2 quintals) in oxen to 46 percent in cocks, the latter of which sold for 9.4 kilograms and 13.7 kilograms of cereals in 2007 and 2016, respectively.

\section{Local versus International Prices}

Part of the changes in the domestic livestock and ASF prices is likely explained by changes in export and import prices of livestock and ASF. Using export data from the Ethiopian Revenue and Customs Authority (ERCA 2017), 
FIGURE 8.11 Export (from Ethiopia) border prices and local prices of live animals/meat, 2007-2015 (US\$ per kilogram)
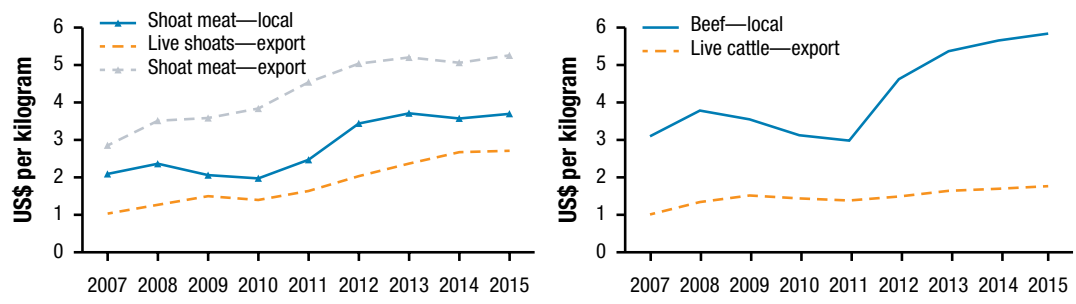

Source: Authors' calculations based on custom data (ERCA 2017) and CSA price data.

Note: "Shoat" combines sheep and goats into a single category.

Figure 8.11 shows to what extent prices, expressed in US dollars per kilogram, have changed over the past 10 years for both locally sold and exported live animals and meats. The data show important increases for live cattle and sheep and goats (shoats) as well as meat both sold locally and exported. Figure 8.12 shows how imported powdered milk prices have changed since 2007 and to what extent similar trends show up in local pasteurized and nonpasteurized milk prices. We find a strong correlation for these prices. The figure suggests that price increases in local markets have at least in part been linked to price increases in international markets.

We present the evolution of prices in international meat markets to understand to what extent the border prices that are noted in Ethiopia are synchronized with international patterns. We look at meat prices in Saudi Arabia, a major export country for Ethiopia; US import prices; and the international meat price index (Figure 8.13). The figure shows significant increases since 2007. However, we also see that meat prices have been coming down in the two most recent years, partly explaining why growth in meat prices in Ethiopia in recent years has been slower.

While it is likely that price increases of some of the livestock categories and ASF in the country have been influenced by international price increases, as Ethiopia is a major exporter of meat, such price increases were also seen for nontraded ASF, such as eggs and milk, and price increases in export destinations seemingly only explain part of these local price rises. In the case of milk, prices of powdered milk in comparison with local milk are very high. ${ }^{19}$ There

19 Retail powdered milk prices in 2016 were around US\$16 per kilogram. Assuming a typical 6.5 liters of liquid milk per 1 kilogram of powdered milk, this would imply a price of US $\$ 2.5$ per liter, significantly above the local unpasteurized (at less than US $\$ 1$ per liter) as well as pasteurized (at just more than US\$1 per liter) milk prices. 
FIGURE 8.12 Import (to Ethiopia) border prices and local prices of milk, 2007-2016

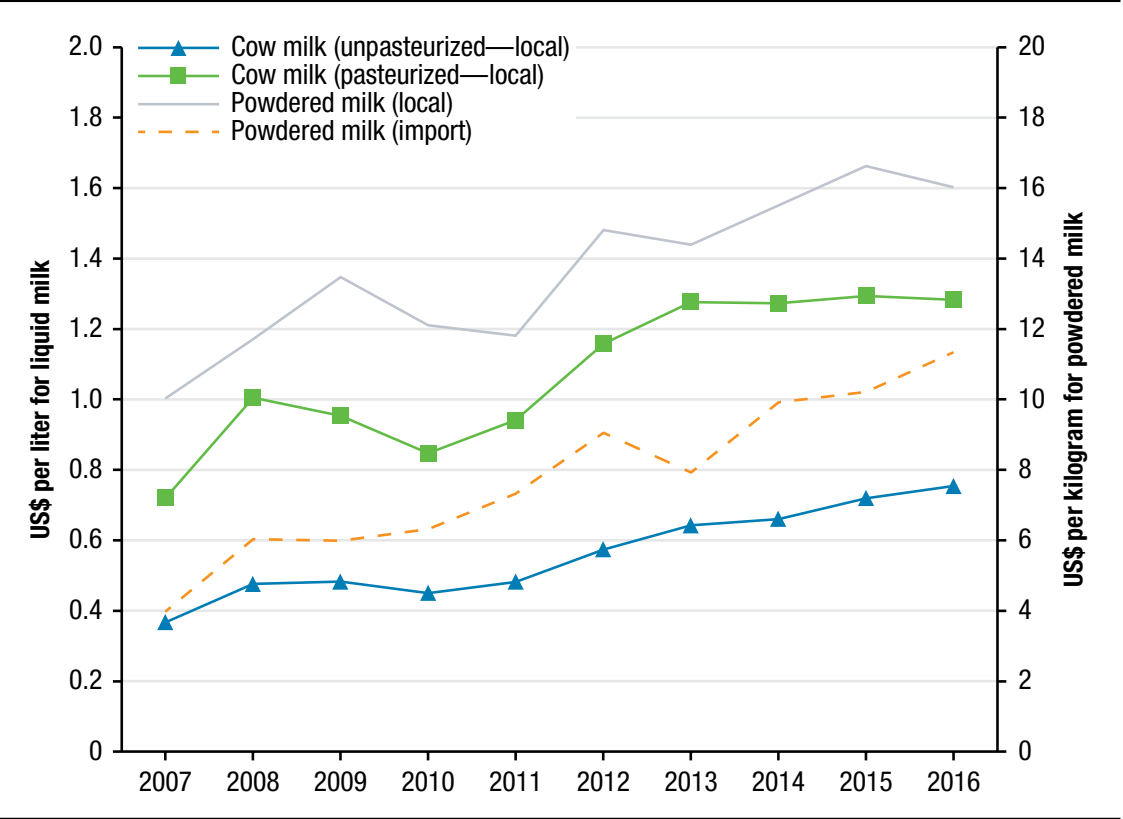

Source: Authors' calculations based on custom data (ERCA 2017) and CSA price data.

FIGURE 8.13 International meat price trends, 2007-2016

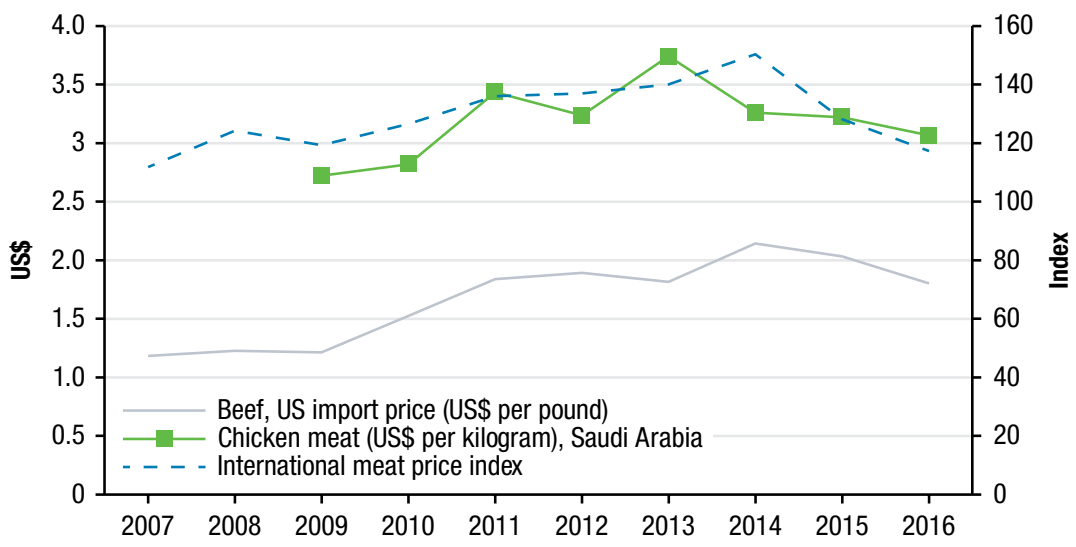

Source: Authors' calculations. 
is likely limited substitution away from these local fresh milk products to imported sources, especially for poorer households, making local milk mostly a nontradable good. For example, the OECD-FAO (2016) estimates that fresh dairy products, with less than 1 percent of production traded, are one of the least traded agricultural commodities.

\section{Conclusion}

Increasing evidence shows that consumption of ASF have important beneficial nutritional impacts. However, only a minority of consumers in developing countries eat such foods, and poorer households especially forego ASF consumption seemingly as prices are perceived to be prohibitively high. Using a large national retail price dataset for Ethiopia that spans the past 10 years, we look at patterns in ASF prices, assess changes over time of ASF and associated livestock prices, and compare these prices with other food products, such as staple cereals. Several typical patterns in ASF and livestock pricing can be highlighted. First, there is price seasonality mostly driven by changes in demand due to religious festivities and fasting periods in the country. Second, there are significant spatial patterns with higher prices in cities and in commercial livestock areas. Third, ASF are relatively expensive. Average prices of ASF per calorie and per kilogram are about ten times as high as for staple cereals, an important consideration in these settings and especially so for the poorer part of the population.

Moreover, we find that real prices of ASF have been increasing rapidly in the past decade, on the order of 33 percent, 36 percent, and 32 percent for beef, milk, and eggs respectively. Such ASF price increases are strongly related with increases in livestock prices. These price trends are in contrast with staple cereal prices that do not show such increases. These are important findings as low prices of food are important in consumption decisions in these environments as shown by consistently high empirical estimates of price elasticities. For example, Tafere et al. (2010) used variation in prices to estimate to what extent consumption patterns change with changing prices, based on the national consumption survey of 2005. They found that most price elasticities were close to -1.0 , suggesting that a 10 percent increase in prices would lead to a 10 percent decrease in consumption. Tafere and Worku (2012) followed a similar methodology to estimate price elasticities for ASF products. They found price elasticities for beef and dairy products as high as -0.73 and -0.67 , respectively. These estimates imply that the price increases seen in the past decade in the country would have led to decreases in per capita consumption 
of beef and dairy products of almost 25 percent, holding other things constant, when we compare the end to the beginning of the decade.

The findings have important implications for policy. There is increasing emphasis on behavioral change communication to stimulate the adoption of more diverse diets in these settings. While these investments are important, households also should be able to afford these more nutritious, but also more expensive, foods. Although Ethiopia has done rather well in improving cereal production in the country and keeping prices of cereals stable, these higher priced foods that might be good for nutrition - as well as for farmers' income-have received relatively limited attention by government and development partners. Relative to the rapid growth in crop output and productivity recorded in the past decade, livestock and ASF output grew slower and productivity stagnated such that their share in agriculture production overall consistently declined (Chapter 5, Negassa et al. 2017). This neglect should be addressed to stimulate further agricultural and nutritional transformation in the country. ${ }^{20}$

Exploring the exact reasons for the increases of livestock and ASF prices should be fertile ground for further research. Several hypotheses can be forwarded. First, yield levels of livestock products are low and changed little during the period studied, and this appears to be because of the low adoption of modern inputs and methods, such as artificial insemination, improved breeds, feeds, and extension, as well as high unplanned deaths of livestock (Chapter 5). This is unlike the increase in crop productivity that resulted from the rapid growth in modern input adoption in the subsector (Chapter 3). Consequently, production has not kept up with the increasing demand for ASF from an increasingly better-off population in some pockets of Ethiopia, leading to such price increases. Second, cropland cultivation has expanded rapidly in Ethiopia. The increasing land pressure might have led to less land being available for (cheaper) grazing and subsequently to the adoption of more expensive purchased feeds (Chapter 5). These higher production costs are reflected in higher livestock and ASF prices. Third, wages are rapidly increasing in rural Ethiopia (Chapter 11). This combined with the lower availability

20 Unlike development policies in the past two decades, the current Growth and Transformation Plan II (GTP II) provides more focus on livestock production and includes reduction of undernutrition as one of its targets. Under GTP II (2015/2016-2019/2020), the Ethiopian government targeted the reduction of stunting levels in young children from 40 percent in 2014/2015 to 26 percent in 2019/2020 (National Planning Commission 2016). Furthermore, improving dietary diversity is one of the focus areas of the Agricultural Growth Program II (2015/2016$2019 / 2020$ ) and is one of the four outcome indicators for the program (Ethiopia, Ministry of Agriculture and Natural Resources 2015). 
of youth that often tend the animals of a household - as they are increasingly enrolled in schools - might also have led to higher costs for keeping animals.

Fourth, while improvements in road and information infrastructure in the country contributed to lower food prices and narrowing of urban-rural price gaps (Chapter 7), this appears to have not happened in the livestock subsector. Moreover, the rapid increase in live animal and meat exports following improvements in access to the rewarding export markets might have contributed to general price rises in the livestock sector. International trade and price movements in destination markets should be looked at as they might have driven some ASF price increases in Ethiopia. However, it should be noted that nontraded ASF showed similar increases. Unraveling the contribution of each of these factors through further research will help with better design of policies in this area with the purpose of making ASF more affordable-especially so for the poorer population.

\section{References}

Arimond, M., and M. T. Ruel. 2004. "Dietary Diversity Is Associated with Child Nutritional Status: Evidence from 11 Demographic and Health Surveys." Journal of Nutrition 134 (10): 2579-2585.

Assefa, T., G. Abebe, I. Lamoot, and B. Minten. 2016. "Urban Food Retailing and Food Prices in Africa: The Case of Addis Ababa, Ethiopia." Journal of Agribusiness in Developing and Emerging Economies 6 (2): 90-109.

Ayele, G., M. A. Jabbar, H. Teklewold, E. Mulugeta, and G. Kebede. 2006. “Seasonal and Inter-Market Differences in Prices of Small Ruminants in Ethiopia." Journal of Food Products Marketing 12 (4): 59-77.

Ayele, G., and K. M. Rich. 2010. Poultry Value Chains and HPAI in Ethiopia. Pro-Poor HPAI Risk Reduction Project Working Paper. Nairobi: International Livestock Research Institute (ILRI)

Ayenew, Y. A., M. Wurzinger, A. Tegegne, and W. Zollitsch. 2009. “Handling, Processing and Marketing of Milk in the North Western Ethiopian Highlands." Livestock Research for Rural Development 21 (7). www.lrrd.org/lrrd21/7/ayen21097.htm.

Bachewe, F., Y. Bai, D. Headey, and W. Masters. Forthcoming. "Measuring the Affordability of Nutrient Adequacy and Dietary Energy in Ethiopia, 2001-2017." Unpublished. 
Bachewe, F., G. Berhane, B. Minten, and A. S. Taffesse. 2015. Agricultural Growth in Ethiopia (2004-2014): Evidence and Drivers. IFPRI-ESSP Working Paper 81. Addis Ababa: International Food Policy Research Institute/Ethiopia Strategy Support Program (IFPRI/ ESSP).

Bellemare, M. F., and C. B. Barrett. 2006. "An Ordered Tobit Model of Market Participation: Evidence from Kenya and Ethiopia." American Journal of Agricultural Economics 88 (2): $324-337$.

Black, R. E., L. H. Allen, Z. A. Bhutta, L. E. Caulfield, M. De Onis, M. Ezzati, C. Mathers, and J. Rivera. 2008. "Maternal and Child Undernutrition Study Group, Maternal and Child Undernutrition: Global and Regional Exposures and Health Consequences." The Lancet 371 (9608): 243-260.

Brinkman, H. J., S. de Pee, I. Sanogo, L. Subran, and M. W. Bloem. 2010. "High Food Prices and the Global Financial Crisis Have Reduced Access to Nutritious Food and Worsened Nutritional Status and Health." Journal of Nutrition 140 (1): 153S-161S.

De Waal, A. 1988. "Famine Early Warning Systems and the Use of Socio-Economic Data." Disasters 12 (1): 81-91.

Dror, D. K., and L. H. Allen. 2011. "The Importance of Milk and Other ASF for Children in Low-Income Countries." Food and Nutrition Bulletin 32 (3): 227-243.

_. 2014. "Dairy Product Intake in Children and Adolescents in Developed Countries: Trends, Nutritional Contribution, and a Review of Association with Health Outcomes." Nutrition Reviews 72 (2): 68-81.

ERCA (Ethiopian Revenues and Customs Authority). 2017. Monthly Import-Export Data. Accessed April 2017. www.erca.gov.et/index.php/import-export-information/.

Ethiopia, CSA (Central Statistical Agency). 2009. Population Census of Ethiopia 2007. Addis Ababa.

-2011. Household Income and Consumption Expenditure Survey. Addis Ababa.

—. 2013. Population Projection of Ethiopia for All Regions at Wereda Level from 2014-2017. Addis Ababa.

- 2015a. Agricultural Sample Survey 2014/15 [2007 E.C.]. Volume 2. Report on Livestock and Livestock Characteristics (Private Peasant Holdings). Addis Ababa.

_.2015b. Agricultural Sample Survey 2014/15 [2007 E.C.]. Volume 4. Report on Land Utilization (Private Peasant Holdings, Meher Season). Addis Ababa.

—.2015c. Agricultural Sample Survey 2014/15 [2007 E.C.]. Volume 1. Report on Area and Production of Crops (Private Peasant Holdings, Meher Season). Addis Ababa.

_.2017a. Country and Regional Level Consumer Price Indices. Addis Ababa. 
- 2017b. Consumer Price Survey. Addis Ababa.

_.2017c. Producer Price Survey. Addis Ababa.

Ethiopia, Ministry of Agriculture and Natural Resources. 2015. Agricultural Growth Program 2 (AGP 2): Program Implementation Manual (PIM). Addis Ababa.

Ethiopia, National Planning Commission. 2016. Growth and Transformation Plan II (GTP II) (2015/16-2019/20): Volume 1: Main Text. Addis Ababa.

FAO (Food and Agricultural Organization of the United Nations). 2015. FAOSTAT database. Rome. http://faostat.fao.org/.

_. 2017. "Livestock and Nutrition." Mimeo. Rome.

Farmer, E. 2010. "End Market Analysis of Ethiopian Livestock and Meat." MicroREPORT \#164. Prepared for USAID. www.value-chains.org/dyn/bds/docs/801/USAID\%20 Ethiopia\%20Livestock\%20End\%20Market\%20Study.pdf.

FVI-Idele (France Vétérinaire Internationale-Institute de l'Elevage). 2016. Complementary Feasibility Study for the Relocation and Modernization of Addis Ababa Abattoirs. Study prepared for Addis Ababa Abattoirs Enterprise (AAAE). Paris.

Givens, D. I. 2010. “Milk and Meat in Our Diet: Good or Bad for Health?” Animal 4 (12): $1941-1952$.

Givens, D. I., K. M. Livingstone, J. E. Pickering, Á. A. Fekete, A. Dougkas, and P. C. Elwood. 2014. "Milk: White Elixir or White Poison? An Examination of the Associations between Dairy Consumption and Disease in Human Subjects." Animal Frontiers 4 (2): 8-15.

Gordon, A., S. D. Tegegne, and M. Tadesse. 2007. Marketing Systems for Fish from Lake Tana, Ethiopia: Opportunities for Improved Marketing and Livelihoods. IPMS (Improving Productivity and Market Success) of Ethiopian Farmers Project Working Paper 2. Nairobi: ILRI.

Hassan, S. 2011. "Futility and Damaging Effects of Ethiopian Price Caps (ANALYSIS)." Accessed October 13, 2016. http://hornofafrica-abdikarim.blogspot.com/2011/01/futility-and -damagingeffects-of.html.

Headey, D., K. Hirvonen, and J. Hoddinott. 2018. "Animal Sourced Foods and Child Stunting." American Journal of Agricultural Economics 100 (5): 1302-1319.

Hirvonen, K. 2016. “Rural-urban Differences in Children's Dietary Diversity in Ethiopia: A Poisson Decomposition Analysis." Economics Letters 147: 12-15.

Hirvonen, K., A. S. Taffesse, and I. W. Hassen. 2016. "Seasonality and Household Diets in Ethiopia." Public Health Nutrition 19 (10): 1723-1730.

Hoddinott, J., H. Alderman, J. R. Behrman, L. Haddad, and S. Horton. 2013. “The Economic Rationale for Investing in Stunting Reduction." Maternal and Child Nutrition 9 (S2): 69-82. 
Hoddinott, J., D. Headey, and M. Dereje. 2015. "Cows, Missing Milk Markets, and Nutrition in Rural Ethiopia." Journal of Development Studies 51 (8): 958-975.

Iannotti, L. L., C. K. Lutter, D. A. Bunn, and C. P. Stewart. 2014. “Eggs: The Uncracked Potential for Improving Maternal and Young Child Nutrition among the World's Poor." Nutrition Reviews 72 (6): 355-368.

Iannotti, L. L., M. Robles, H. Pachón, and C. Chiarella. 2012. "Food Prices and Poverty Negatively Affect Micronutrient Intakes in Guatemala." Journal of Nutrition 142 (8): 1568-1576.

Jabbar, M., S. Benin, E. Gabre-Madhin, and Z. Paulos. 2008. "Market Institutions and Transaction Costs Influencing Trader Performance in Live Animal Marketing in Rural Ethiopian Markets." Journal of African Economies 17 (5): 747-764.

Jin, M., and L. L. Iannotti. 2014. "Livestock Production, Animal Source Food Intake, and Young Child Growth: The Role of Gender for Ensuring Nutrition Impacts.” Social Science and Medicine 105: 16-21.

Kim, S. S., R. Rawat, E. M. Mwangi, R. Tesfaye, Y. Abebe, J. Baker, E. A. Frongillo, M. T. Ruel, and P. Menon. 2016. "Exposure to Large-Scale Social and Behavior Change Communication Interventions Is Associated with Improvements in Infant and Young Child Feeding Practices in Ethiopia." PLoS ONE 11 (10): e0164800.

Leroy, J. L., and E. A. Frongillo. 2007. "Can Interventions to Promote Animal Production Ameliorate Undernutrition?” Journal of Nutrition 137 (10): 2311-2316.

Little, P. D., D. N. Debsu, and W. Tiki. 2014. "How Pastoralists Perceive and Respond to Market Opportunities: The Case of the Horn of Africa." Food Policy 49: 389-397.

Mekasha, A., B. Gerard, K. Tesfaye, L. Nigatu, and A. J. Duncan. 2014. "Inter-connection between Land Use/Land Cover Change and Herders'/Farmers' Livestock Feed Resource Management Strategies: A Case Study from Three Ethiopian Eco-environments." Agriculture, Ecosystems and Environment 188: 150-162.

Minten, B., Y. Habte, S. Tamru, and A. Tesfaye. 2018. Transforming Agri-Food Systems in Ethiopia: Evidence from the Dairy Sector. ESSP Working Paper 129. Addis Ababa: International Food Policy Research Institute (IFPRI).

Minten, B., D. Stifel, and S. Tamru. 2014. "Structural Transformation of Cereal Markets in Ethiopia." Journal of Development Studies 50 (5): 611-629.

Msangi, S. 2016. "Results IMPACT Model IFPRI.” Presentation FAO. Unpublished, FAO, Rome. National Bank of Ethiopia. 2016. Annual Report 2015/16. Addis Ababa.

Negassa, N., F. Bachewe, A. S. Taffesse, and M. Dereje. 2017. An Assessment of the Livestock Economy in Mixed Crop-Livestock Production Systems in Ethiopia. IFPRI-ESSP Working Paper 101. Addis Ababa: IFPRI/Ethiopia Strategy Support Program (ESSP). 
Negassa, A., S. Rashid, B. Gebremedhin, and A. Kennedy. 2012. "Livestock Production and Marketing." In Food and Agriculture in Ethiopia: Progress and Policy Challenges, edited by P. Dorosh and S. Rashid, 159-189. Philadelphia: University of Pennsylvania Press on behalf of IFPRI.

Nyoni, N. M. B., S. Grab, and E. R. Archer. 2019. "Heat Stress and Chickens: Climate Risk Effects on Rural Poultry Farming in Low-Income Countries." Climate and Development 11 (1): $83-90$.

OECD (Organisation for Economic Co-operation and Development)-FAO. 2016. OECD-FAO Agricultural Outlook 2016-2025. Paris: OECD; Rome: FAO.

Randolph, T. F., E. Schelling, D. Grace, C. F. Nicholson, J. L. Leroy, D. C. Cole, M. W. Demment, A. Omore, J. Zinsstag, and M. Ruel. 2007. "Role of Livestock in Human Nutrition and Health for Poverty Reduction in Developing Countries.” Journal of Animal Science 85 (11): 2788-2800.

Rashid, S., and N. Minot. 2010. "Are Staple Food Markets in Africa Efficient? Spatial Price Analyses and Beyond." Paper presented at the COMESA policy seminar "Food Price Variability: Causes, Consequences, and Policy Options," Maputo, January 25-26.

Rashid, S., and A. Negassa. 2012. "Policies and Performance of Ethiopian Cereal Markets." In Food and Agriculture in Ethiopia: Progress and Policy Challenges, edited by P. Dorosh and S. Rashid, 53-83. Philadelphia: University of Pennsylvania Press.

Sadler, K., and A. Catley. 2009. Milk Matters: The Role and Value of Milk in the Diets of Somali Pastoralist Children in Liben and Shinile, Ethiopia. Addis Ababa: Feinstein International Center, Tufts University and Save the Children.

Sahn, D. E. 1989. Seasonal Variability in Third World Agriculture: The Consequences for Food Security. London: IFPRI; Baltimore: Johns Hopkins University Press.

SID-Consult. 2010. "Market Assessment and Value Chain Analysis in Benishangul-Gumuz Regional State, Ethiopia.” Mimeo. Accessed December 5, 2017. www.cangoethiopia.org/ assets/docs/BG\%20Market\%20Assessment\%20Final\%20Report\%20300510.pdf.

Tadesse, K., B. Lanos, and A. MasAsparisi. 2014. “Analysis of Price Incentives for Live Cattle in Ethiopia." Technical notes series, MAFAP (Monitoring and Analysing Food and Agricultural Policies), FAO, Rome.

Tafere, K., A. S. Taffesse, S. Tamiru, N. Tefera, and Z. Paulos. 2010. Food Demand Elasticities in Ethiopia: Estimates Using Household Income Consumption Expenditure (HICE) Survey Data. ESSP II Working Paper 11. Addis Ababa: IFPRI.

Tafere, K., and I. Worku. 2012. Consumption Patterns of Livestock Products in Ethiopia: Elasticity Estimates Using HICES (2004/05) Data. ESSP II. Addis Ababa: IFPRI and Ethiopian Development Research Institute. 
Tefera, T. L., R. Puskur, D. Hoekstra, and A. Tegegne. 2010. Commercializing Dairy and Forage Systems in Ethiopia: An Innovation Systems Perspective. ILRI Working Paper 17. Nairobi: ILRI.

Tegegne, A., B. Gebremedhin, D. Hoekstra, B. Belay, and Y. Mekasha. 2013. Smallholder Dairy Production and Marketing Systems in Ethiopia: IPMS Experiences and Opportunities for Market-Oriented Development. IPMS (Improving Productivity and Market Success) of Ethiopian Farmers Project Working Paper 31. Nairobi: ILRI.

Teklewold, H., G. Legese, D. Alemu, and A. Negasa. 2009. Determinants of Livestock Prices in Ethiopian Pastoral Livestock Markets: Implications for Pastoral Marketing Strategies. Contributed paper prepared for presentation at the International Association of Agricultural Economists Conference, Beijing, China.

Tilahun, H., and E. Schmidt. 2012. Spatial Analysis of Livestock Production Patterns in Ethiopia. ESSP II. Addis Ababa: IFPRI.

UN Comtrade (United Nations-Comtrade). 2017. UN Comtrade Database. Accessed April 28, 2017. http://comtrade.un.org/.

USAID. 2013. "Agricultural Growth Program — Livestock Market Development. End Market Analysis for Meat/Live Animals, Leather and Leather Products, Dairy Products Value Chains." Expanding Livestock Markets for the Small-Holder Producers. Prepared by the AGP-Livestock Market Development Project of CFNA (Cultivating New Frontiers in Agriculture), Washington, DC.

Warren, A. M., and E. A. Frongillo. 2017. "Mid-level Actors and Their Operating Environments for Implementing Nutrition-Sensitive Programming in Ethiopia." Global Food Security 13: $66-73$.

Weaver, C. M. 2014. "How Sound Is the Science Behind the Dietary Recommendations for Dairy?" American Journal of Clinical Nutrition 99 (5): 1217S-1222S.

Worku, I., M. Dereje, B. Minten, and K. Hirvonen. 2016. Diet Transformation in Africa: Evidence from Ethiopia. IFPRI-ESSP Working Paper 87. Addis Ababa: IFPRI/ESSP.

World Bank. 2014. Ethiopia: Poverty Assessment. Report No. AUS6744. Poverty Global Practice. Africa Region. World Bank. Washington, DC. 
